Article

\title{
Earth Observation for Monitoring, Reporting, and Verification within Environmental Land Management Policy
}

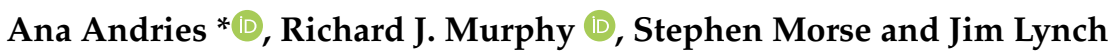 \\ Centre for Environment and Sustainability, Faculty of Engineering and Physical Sciences, University of Surrey, \\ Guildford GU2 7XH, UK; rj.murphy@surrey.ac.uk (R.J.M.); s.morse@surrey.ac.uk (S.M.); \\ j.lynch@surrey.ac.uk (J.L.) \\ * Correspondence: a.andries@surrey.ac.uk
}

Citation: Andries, A.; Murphy, R.J.;

Morse, S.; Lynch, J. Earth Observation for Monitoring, Reporting, and Verification within Environmental Land Management Policy. Sustainability 2021, 13, 9105. https:// doi.org/10.3390/su13169105

Academic Editor: Andrew Kirby

Received: 1 July 2021

Accepted: 9 August 2021

Published: 14 August 2021

Publisher's Note: MDPI stays neutral with regard to jurisdictional claims in published maps and institutional affiliations.

Copyright: (c) 2021 by the authors. Licensee MDPI, Basel, Switzerland. This article is an open access article distributed under the terms and conditions of the Creative Commons Attribution (CC BY) license (https:// creativecommons.org/licenses/by/ $4.0 /)$.

\begin{abstract}
The main aim of the new agricultural scheme, Environmental Land Management, in England is to reward landowners based on their provision of 'public goods' while achieving the goals of the 25 Year Environment Plan and commitment to net zero emission by 2050. Earth Observation (EO) satellites appear to offer an unprecedented opportunity in the process of monitoring, reporting, and verification (MRV) of this scheme. In this study, we worked with ecologists to determine the habitat-species relationships for five wildlife species in the Surrey Hills 'Area of Outstanding Natural Beauty' (AONB), and this information was used to examine the extent to which EO satellite imagery, particularly very high resolution (VHR) imagery, could be used for habitat assessment, via visual interpretation and automated methods. We show that EO satellite products at $10 \mathrm{~m}$ resolution and other geospatial datasets enabled the identification and location of broadly suitable habitat for these species and the use of VHR imagery (at 1-4 m spatial resolution) allowed valuable insights for remote assessment of habitat qualities and quantity. Hence, at a fine scale, we obtained additional habitats such as scrub, hedges, field margins, woodland and tree characteristics, and agricultural practices that offer an effective source of information for sustainable land management. The opportunities and limitations of this study are discussed, and we conclude that there is considerable scope for it to offer valuable information for land management decision-making and as support and evidence for MRV for incentive schemes.
\end{abstract}

Keywords: very high resolution satellite data; earth observation; habitat suitability; habitat assessment; Environmental Land Management

\section{Introduction}

The sustainability of land-use and -cover systems are determined by the interaction between natural resources (including soils, water, plants, and wildlife), climate, and human activities while ensuring a long-term productivity of these resources and maintaining a balance within the environmental functions [1]. Hence, sustainable land management (SLM) has been debated extensively in the literature [2-4] and can be defined as "a knowledgebased procedure that helps to integrate land, water, biodiversity, and environmental management to meet rising food and fibre demands while sustaining ecosystem services and livelihoods" [5]. At the global level, the United Nations Food and Agriculture Organisation (FAO) supports integrated land resource planning strategies through a wide range of comprehensive approaches, tools, and measures adapted to different biophysical and socio-economic contexts when aiming for sustainable land resilience and avoid degradation [6].

Land-use policy impacts land management and therefore affects the extent and state of ecosystem services [7]. The importance of decision support for mainstreaming and scaling up of SLM formulated by FAO led to each country shaping its own set of policies, programmes, and schemes that determine the extent to which SLM is taken into account in resource-management decisions [8]. Hence, at the national level, the UK Environment 
Bill [9] and Agriculture Bill [10] set the foundations for implementing the 25 Year Environment Plan and led to the establishment of the Environmental Land Management (ELM) scheme.

The ELM scheme is a new programme of intensive policy development over the period 2019-2024 with implementation post-2025 by the Department for Environment, Food and Rural Affairs (DEFRA) replacing the previous EU Common Agricultural Policy. The ELMs is based on three schemes, Sustainable Farming Incentive (SFI), Local Nature Recovery (LNR), and Landscape Recovery (LR). The overall aim of these is to use public money to pay farmers and land managers in England to deliver a set of 'public goods' that cover clean air, clean and plentiful water, thriving plants and wildlife, protection from and mitigation of environmental hazards, beauty, heritage and engagement, and mitigation of and adaptation to climate change [11]. Nevertheless, land-use management and decision making that prioritises only one type of ecosystem service without considering those occurring within and between ecosystems results in policy failure [12].

While 'public goods' and 'ecosystem services' have different theoretical backgrounds $[13,14]$ from an environmental perspective, DEFRA's range of public goods are often identified with some of the typical ecosystem services $[15,16]$. Therefore, ecosystem services are known as the benefits obtained directly or indirectly from ecosystems that support human life and enhance social welfare [12]. They are typically categorised as supporting services, provisioning services, regulating services, and services that support cultural needs.

In terms of measuring biodiversity conservation and ecosystem services, there are freely available integrated modelling tools such as Integrated Valuation of Ecosystem Services and Trade-offs (InVEST) [17], Co\$tingNature [18], Multiscale Integrated Model of Ecosystem Services [19], Protected Area Benefits Assessment Tool (PA-BAT) [20], Ecosystem Services Toolkit (EST) [21], Toolkit for Ecosystem Services Site-based Assessment (TESSA) [22], Multiscale Integrated Model of Ecosystem Services (MIMES) [23], and Artificial Intelligence for Ecosystem Services (ARIES) [24]. All these can help with measuring, modelling, and valuing ecosystem services and thus help support decision-making about resources management and planning [25].

Land-use management activities have profoundly altered many ecosystems and therefore SLM approaches, and nature-based solutions are needed across policies [26,27]. Integrating nature-based solutions has been well debated in the literature within a range of applications on land-use management [28], land and soil degradation [28], urban planning [26,29], and polluted land [30]. Likewise, delivering nature-based interventions can maximise ecosystem services and lead towards net zero greenhouse gas emissions [28,31].

As part of the ELM policy development, DEFRA established 57 Test and Trails with stakeholders to understand how ELMs could be shaped in order to work in a real-life environment across a wide range of circumstances and to help understand the barriers and opportunities of new approaches [32]. The Surrey Hills Area of Outstanding Natural Beauty (SH-AONB) Test and Trial, entitled 'Making Space for Nature', is one of these 57 Test and Trails and is one of the 12 AONB-based ones that together make up the largest Defra Test and Trial project group for the ELM scheme. The main aim of this test and trial is to understand what local nature recovery and enhanced access represent for a 'designated landscape' and how this can be delivered through ELMs [33].

Currently, DEFRA [16,32] is exploring a range of ways for monitoring, reporting, and verification (MRV) of ELM scheme agreements. They are aware that ground-based surveys and physical inspections can be prohibitively expensive, and they want to consider the use of satellite and geospatial data, alongside other technologies that can offer cost-effective processes for the MRV of ELM and similar activities [16,34,35]. The spectral, spatial, and temporal resolution capabilities of modern Earth Observation (EO) satellites certainly appear to offer an unparalleled opportunity relevant to such ELM and MRV application through their capacities to assess: 
- biodiversity and habitat type [36-40]

- habitat quality [41,42] and model habitat suitability $[43,44]$

- $\quad$ species identity and diversity [45-50]

- $\quad$ species behaviour $[49,51]$.

Habitat suitability models seek to predict the optimal habitat for a species based on the assessment of habitat attributes such as habitat structure, habitat type, and spatial arrangements between habitat features. The models use established correlations between the presence of particular species and known ecological niche elements to analyse geographical space (e.g., from earth observation at various scales) to locate those same niche elements. This can then be used to create predictive location maps and other representations of the distribution and quantities of relevant habitat for a given species or group of species [44,52].

According to Turner et al. [53], there are two general approaches to quantify and model biodiversity using satellite and airborne remote sensing: direct mapping of species composition (based on tree canopy) and land use and cover [54-56] and indirect sensing by using environmental variables proxies such as: primary productivity (chlorophyll and ocean colour), climate (rainfall, soil moisture, and phenology), habitat structure (topography and vertical canopy structure) [44]. These approaches can be performed using visual photo/image interpretation [57] and computing/automated methods [57,58]. Visual interpretation is a 'manual' method based on the visual detection, identification, and spatial localisation of different objects and terrain shapes [59], whilst the automated methods typically use supervised and unsupervised image classification approaches (object and pixel image analysis) via classification algorithms (e.g., maximum-likelihood, support vector machine, random forest, and neural networks) [55,60-62].

Spatial resolution is an important attribute for the remote assessment of opportunities for biodiversity as it describes the level of spatial detail which can be seen in the image. Generally, higher spatial detail requires a sensor with a narrower field of view, hence less spatial coverage per image scene. Satellite sensors with a smaller field of view (e.g., Worldview and Superview have a $16 \mathrm{~km}$ swath) are generally constrained by low revisit times, unless the satellite is combined with phased orbit of the satellite constellation, which can offer a two day revisit for any point on Earth. Coarser spatial resolution sensors can image larger areas (e.g., Sentinel-2 can image strips $290 \mathrm{~km}$ wide) in one overpass of the satellite sensor with more regular repeat cycles [63]. There are also several important biodiversity trade-offs when considering the spatial resolution of a satellite sensor. For example, lowresolution data are perfectly adequate for monitoring status of broad land cover (LC)/ use (LU) [64] and land change at regional level [65], while higher-resolution data are often desirable for monitoring at a local scale, individual protected areas [66,67] and agricultural practices [68], habitat loss, fragmentation and degradation, and ecosystem services [69,70] and for substituting for physical inspection [34,68]. Moreover, Mairota et al. [47] demonstrated that VHR satellite data can help mapping biodiversity and modelling habitat across different scales (landscape, plot, and patch) which can be used for identifying specific taxonomic groups. One other benefit of using VHR satellite data $(0.5-5 \mathrm{~m}$, depending on the optical sensor) is to discriminate some aspects of the habitat characteristics which normally cannot be seen at the coarser resolution [37]. For instance, case studies have been carried out using VHR optical satellite or aerial imagery for the mapping and monitoring of moorland to map vegetation patterns, evidence of ditching, and degree of peat exposure or burn histories [71,72]. 
The potential for assessing biodiversity and ecosystem status can be obtained through EO-derived land-cover and land-use datasets, spatial information, and in situ data [37]. In terms of the land-cover classification system at the global scale (refers to scales smaller than 1:250,000 and using NOAA Advanced Very High Resolution Radiometer (AVHRR) satellites), the most representative examples are USGS product [73], EarthSat GeoCover Land Cover Legend [74], the UN/FAO Land Cover Classification System [75], Global Observation of Forest Cover [76], and Global Observation of Land Cover Dynamics (GOFC/GOLD) [77]. Furthermore, land-cover classification at a regional scale (between 1:250,000 and 1:100,000) often use a medium spatial resolution from satellites such as Landsat TM, SPOTHRV / XS, IRS-1C/LISS, Landsat ETM+, and MODIS, offering classification systems such as CORINE [78] and AFRICOVER [79]. At the national scale, land-cover classification systems are available at smaller scales (between 1:5000-1:10,000) and are commonly based on remote sensing data and in situ surveys. Some products of land-cover classification systems at the national scale are National Land Cover Data Classification System [80], National Land Survey Classification System, and Centre for Ecology and Hydrology (CEH) Land Cover Map [81].

The Centre for Ecology and Hydrology $(\mathrm{CEH})$ has developed its Land Cover Map spatial framework, which uses satellite data from 2015-2019 from the European Space Agency's Copernicus Sentinel-1 and Sentinel-2 satellites. These have a high resolution (10 $\mathrm{m}$ ) enabling the distinction between 21 land-cover classes on the basis of Sentinel imagery and linked to Biodiversity Action Plan (BAP) Broad Habitats [82]. However, it has been noted [83] that discrepancies can exist in the habitat terminology, revealing the need for additional ecological expert knowledge and potentially VHR data to help resolve such ambiguities (e.g., in plant height estimations). VHR data have a wide application across many sectors, including assessing biodiversity and habitat quality [47]. While UK CEH LC and Crops are products that have a dynamic role for identifying main habitats, land cover/use and change and connectivity, and to support land parcel boundary mapping and principal crop types, VHR imagery can capture field boundary features (e.g., hedgerows and field margins), seasonal aspects related to agricultural management practices, vegetation patterns, evidence of ditches, forest canopy, etc. [72,83,84].

Insufficient collaboration with biodiversity experts is frequently cited as a limitation in using remote sensing for monitoring biodiversity and developing relevant indicators [85]. A deep understanding of habitat-species relationships must be available to use remotely sensed information effectively. Gaps still exist in our knowledge regarding the potential of EO imagery at the higher resolutions for projects such as the SH-AONB 'Making Space for Nature' Defra Test and Trial:

1. VHR satellite data use in identifying the availability of suitable and connected habitat, and

2. how effectively do EO approaches at the highest resolutions add new insights to overall habitat assessments for various species of importance for biodiversity conservation and recovery.

Our aim in the present research was, therefore, to work with ecologists to establish habitat criteria for five example species/species groups (henceforth referred to as the 'species') and then to use this information to examine the potential role of EO in habitat evaluation for these species at particular sites and more widely in the SH-AONB. The research was conducted in three linked steps (see Figure 1): Step 1, knowledge acquisition of species-habitat requirements; Step 2, use of readily-available EO and similar resources to evaluate broad habitat suitability and connectivity for the species; and Step 3, exploration of the additional contribution of the increasingly available Very High Resolution (VHR) EO data (0.7-4 $\mathrm{m}$ in this study) for habitat assessment. 


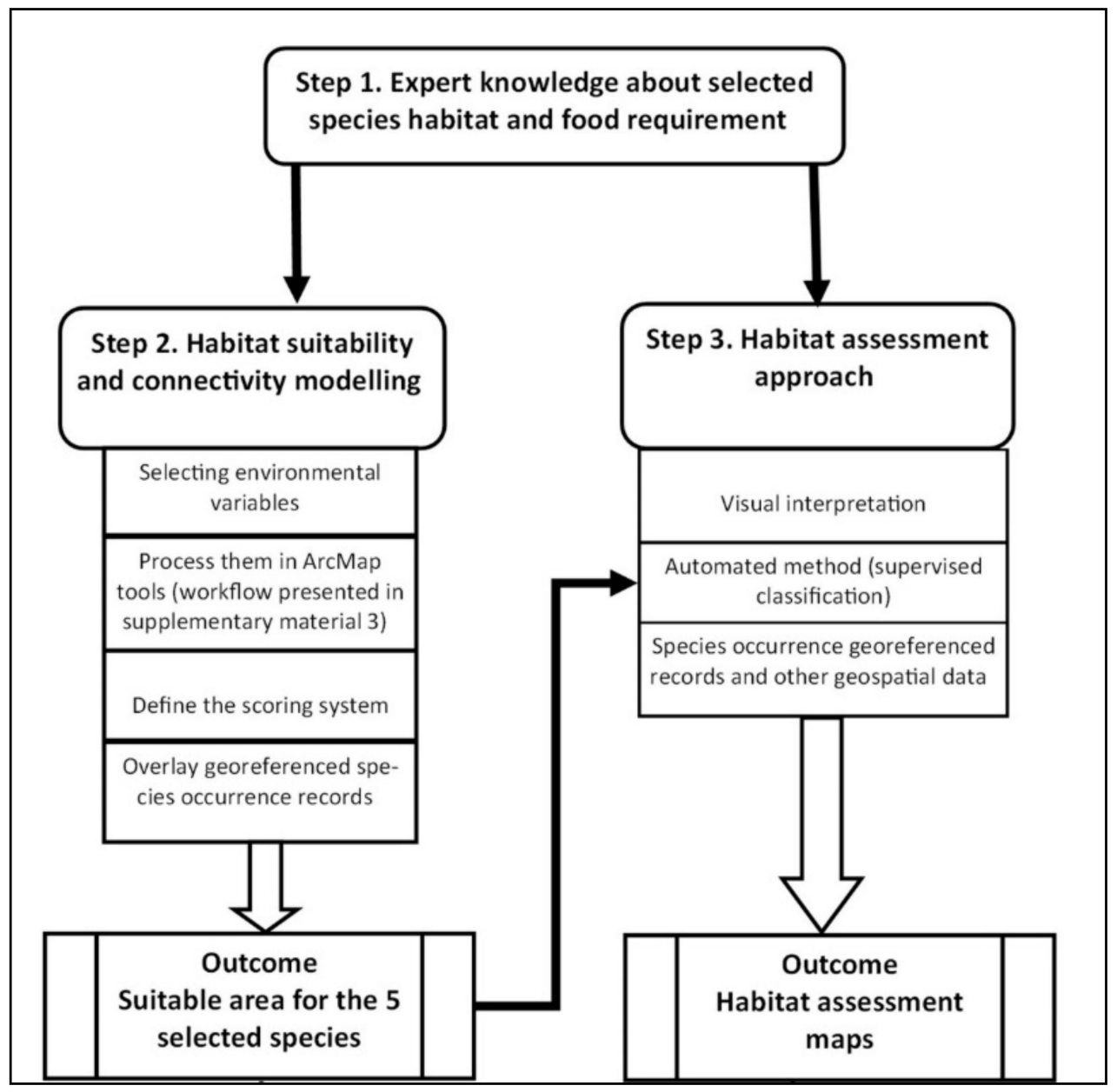

Figure 1. Workflow, analysis, and outcomes in this study.

\section{Materials and Methods}

Figure 1 summarises the overall research workflow, methods, and outcomes of the three steps applied in this study.

\subsection{Study Area and Sites Selected}

The Surrey Hills was one of the first landscapes in the UK to be 'designated' as an 'Area of Outstanding Natural Beauty' (AONB) in 1958. It should be noted here that AONB is not a subjective term of the authors but a formal one created by the UK Government. In June 2000, it was confirmed that AONBs have the same level of landscape quality and share the same level of protection as National Parks, and the primary purpose of an AONB is stated as 'to conserve and enhance the natural beauty of the area'. There are 34 AONBs in England, and together they cover 15\% of the total land area. Notably, AONBs and National Parks are found in Category V-landscapes managed mainly for conservation and recreation - of the International Union for the Conservation of Nature and Natural Resources' global network of protected landscapes [86].

The Surrey Hills AONB covers $422 \mathrm{~km}^{2}$ with myriad landowners and community nature spaces. These include a wide diversity of broad priority habitats in the UK Biodiversity Action Plan (BAP) such as ancient woodland, broadleaved mixed and yew woodland, coniferous woodland, arable and horticulture, improved grassland, acid grassland, calcareous grassland, heather, freshwater, built-up areas, and traditional orchards. These provide habitat for BAP priority species, 85 specially protected species, and at least 300 species recognised as being a priority for conservation [87]. 
We selected for intensive study three farm sites within the SH-AONB area that comprise different habitats and biodiversity opportunities (Figure 2):

- Hampton Estate, located in the Greensand Plateau: Shackleford ( 739 ha), 51.2116 N, $0.7034^{\circ} \mathrm{W}$ (Site 1) Sondes Place Farm, near Dorking, between Greensand Valley (Pippbrook and Tillingbourne) and The North Downs ( 78.6 ha), 51.2304 ${ }^{\circ} \mathrm{N}, 0.3425^{\circ} \mathrm{W}$, (Site 2)

- Landbarn Farm also located near Dorking, between Greensand Valley (Pippbrook and Tillingbourne) and The North Downs ( 100 ha), 51.2309 $\mathrm{N}, 0.3740^{\circ} \mathrm{W}$, (Site 3).

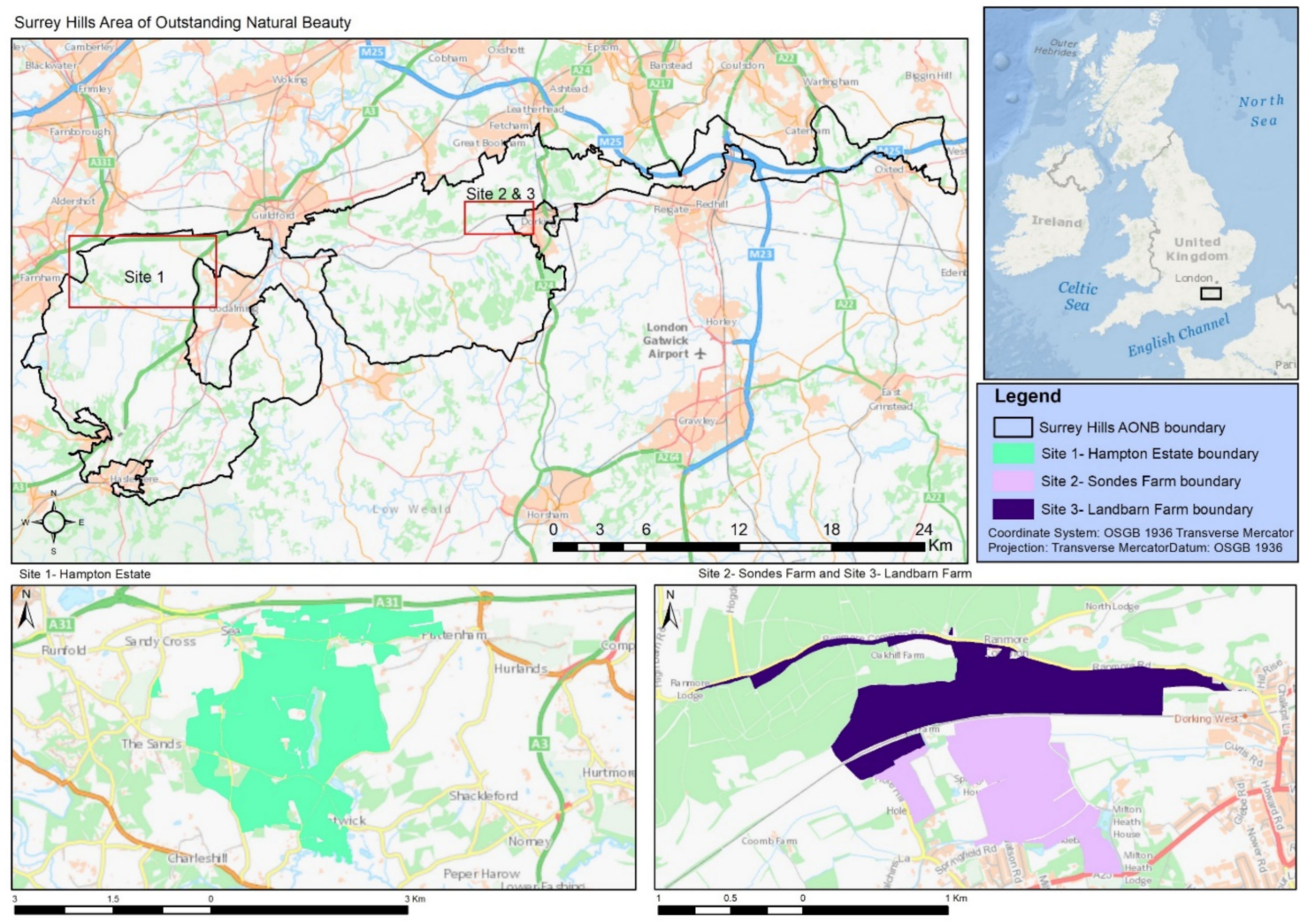

Figure 2. Locations of SH-AONB and the three intensive study sites.

\subsection{Resources for Readily Available EO and Other Data (Research for Step 2)}

The following datasets were used for Step 2 and to complement the use of VHR imagery for the habitat suitability assessment carried out in Step 3 of this research:

2.2.1. UK Centre for Ecology and Hydrology Land Cover Map 2019 (LCM2019) (20 m Classified Pixels) and Crop 2019

The Centre for Ecology and Hydrology (CEH) has recently made available the UK Land Cover Map 2019 (LCM2019) [56,88], a product based on satellite images (mainly Sentinel-2), digital cartography, and machine-learning techniques (e.g., bootstrap training combined with random forest classifier). LCM2019 provides information about physical materials on the Earth's surface; these can be natural such as vegetation, freshwater, inland rocks, etc., and non-natural materials such as buildings or urbanised areas. LCM2019 has 21 classes using similar UK BAP Broad Habitats categories except for a couple of inconsistencies. Mapping relationships and discrepancies in definitions between the $\mathrm{CEH}$ LC 2019 and UK BAP Broad Habitats categories are outlined in [56,88]. 
The SH-AONB is covered by 11 of the CEH LC classes illustrated and listed in Figure 3 for the whole SH-AONB and for our three intensive study sites. Further details of the SH-AONB LC and UK BAP Broad Habitats classes are given in Supplementary Materials (Table S1) [56,82]. UK CEH Crops 2019 product was obtained using Sentinel-2. The crops from 2019 in SH-AONB were identified as winter wheat, winter oats, spring wheat, winter barley, spring barley, oilseed rape, field beans, potatoes, maize, peas, and other crops (which might include other cereals, root crops, early potatoes, and vegetables) (Figure 4).

The UK CEH LCM2019 and Crops2019 products were obtained free of charge in raster and vector format from the Digimap Edina platform [89] under University of Surrey's license.

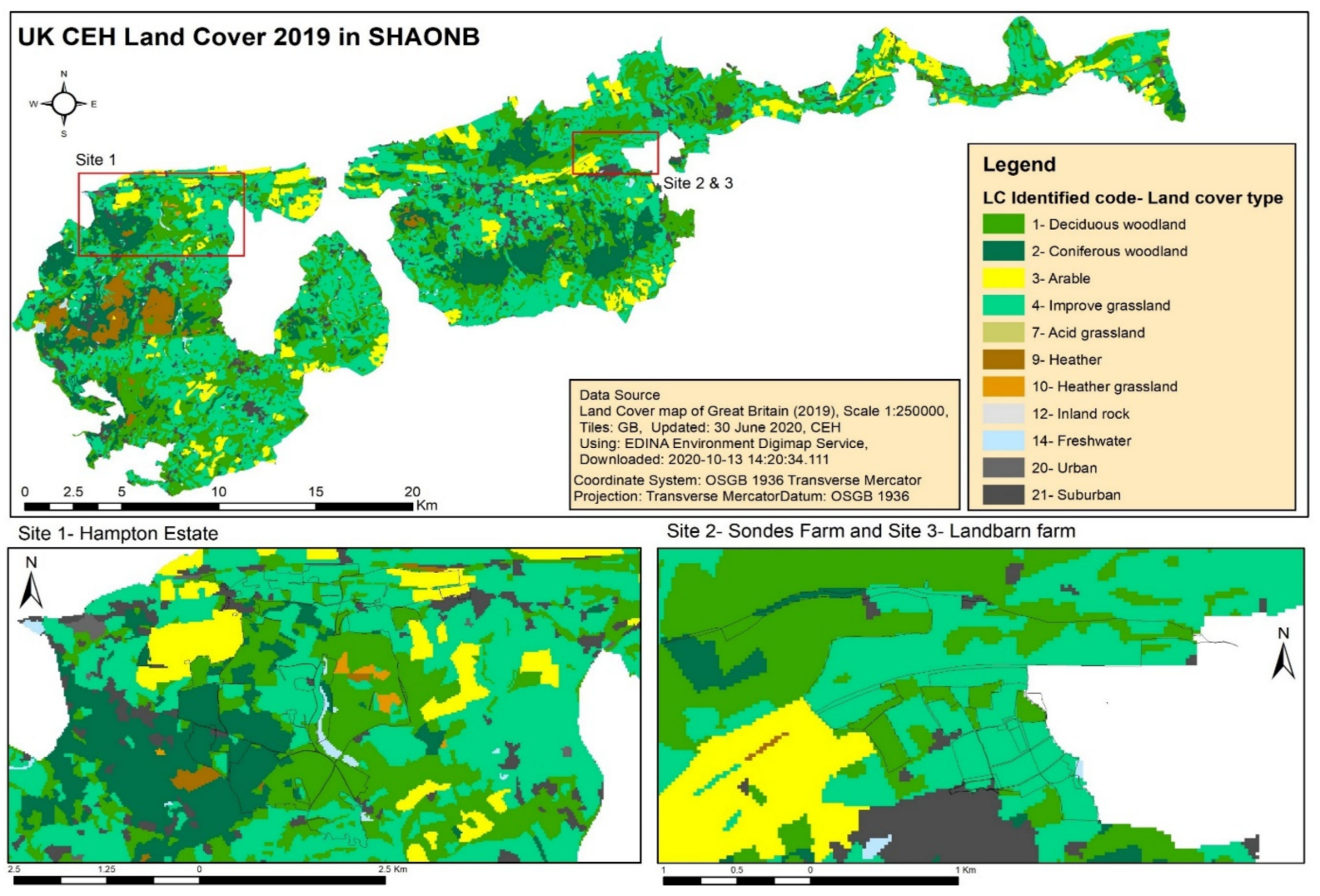

Figure 3. UK CEH Land Cover classes in the SH-AONB (locations of the three intensive study sites shown in red boxes).

\subsubsection{Priority Habitat Inventory (England)}

This is a spatial dataset that describes the geographic extent and location of 41 habitats, which is a separate classification from BAP Broad Habitats relevant to the Natural Environment and Rural Communities Act (2006). Among these 41 classes, we extracted only the calcareous grassland (chalk grassland) that helped for modelling the habitat suitability for the Small Blue butterfly. The data are free open access provided by Natural England [90].

\subsubsection{OS Open Rivers and Open Street Map GIS Shapefiles}

We extracted the watercourses from OS Open Rivers dataset provided by DigiMap Edina [89] and small roads such as footpaths and bridleways from Open Street Map [91], which has been used mainly for assessing the habitat suitability for dragonflies and damselflies and the silver-washed fritillary butterfly. 

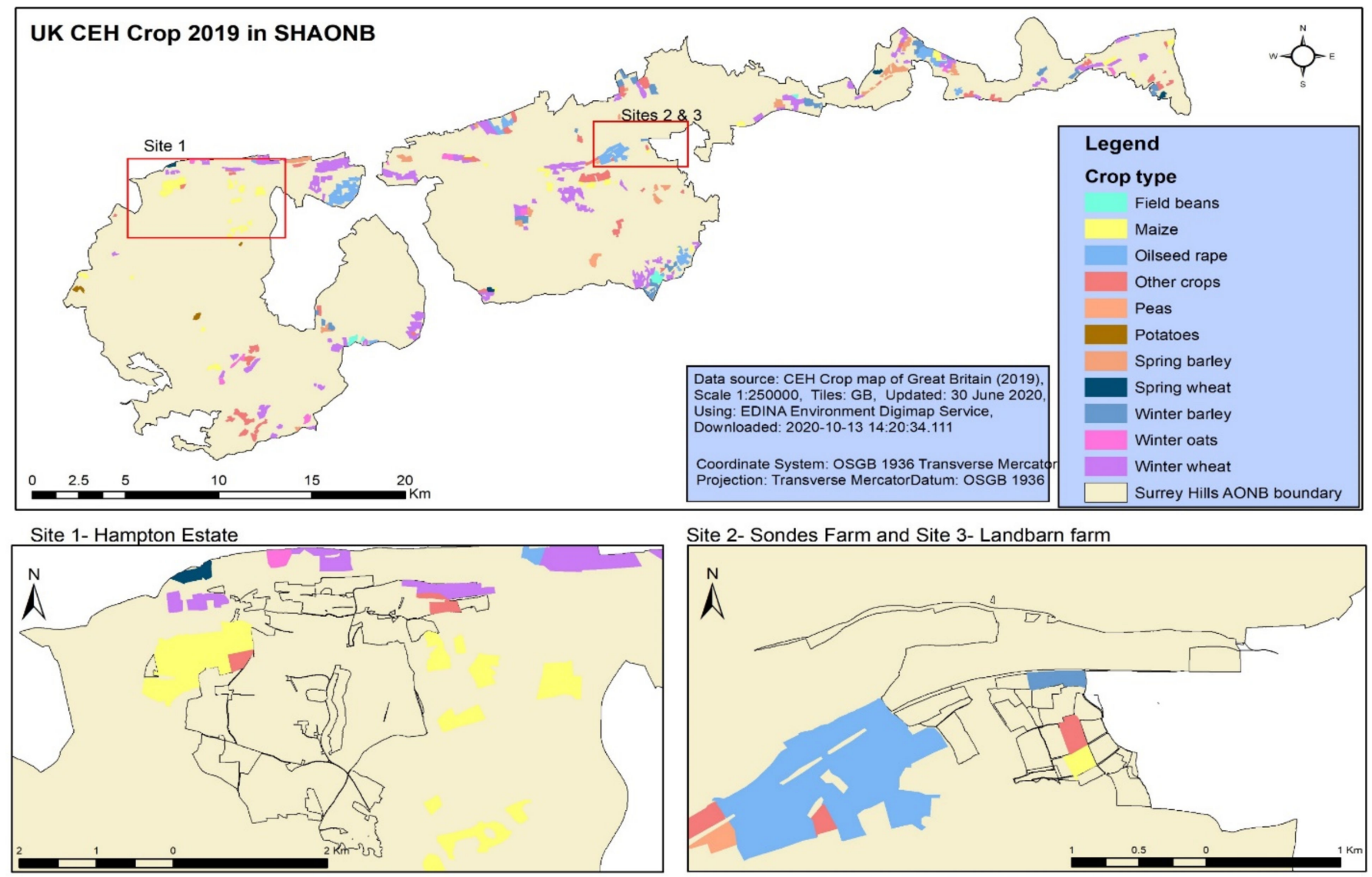

Figure 4. UK CEH Crops 2019 in SH-AONB and the three intensive study sites (red boxes).

\subsubsection{Digital Elevation Model (DEM)}

The DEM generally refers to a representation of a bare terrain surface or a subset of it, excluding features such as vegetation, buildings, or bridges. DEM is often useful for flood disaster evaluations or water-flow estimation models, land-use studies, and geological applications, aspect, slope, etc. DEM can be obtained from different data types (e.g., satellites and Lidar), but in this study, we used Google Earth Engine (GEE) [92], which provides free open access to the NASA Shuttle Radar Topography Mission (SRTM) Digital Elevation $30 \mathrm{~m}$. SRTM digital elevation data are based on an international research effort that obtained digital elevation models on a near-global scale [93].

\subsubsection{Species Occurrence Records}

We obtained occurrence data for all five species from the past 5-12 years. These datasets were requested from a variety of organisations (Table 1). The original records requested were collected from crowd-sourcing biodiversity data via the NBN Atlas and iRecord (dragonflies and damselflies) and conducted surveys (dormouse, skylark, and butterflies). For instance, the UK British Monitoring Scheme (UKBMS), which is run by $\mathrm{CEH}$, Butterfly Conservation, British Trust for Ornithology, and Joint Nature Conservation Committee (JNCC), uses a structured methodology to monitor at least 56 butterfly species across over 4000 UK sites. 
Table 1. Selected species occurrence records and their providers.

\begin{tabular}{ccccc}
\hline Species & $\begin{array}{c}\text { Species } \\
\text { Scientific Name }\end{array}$ & $\begin{array}{c}\text { Main Habitat } \\
\text { Requirement }\end{array}$ & $\begin{array}{c}\text { Provider of the } \\
\text { Species Occurrence } \\
\text { Records }\end{array}$ & $\begin{array}{c}\text { Collection } \\
\text { Period }\end{array}$ \\
\hline $\begin{array}{c}\text { Silver-washed } \\
\text { fritillary } \\
\text { butterfly }\end{array}$ & Argynnis paphia & Woodland/scrub & $\begin{array}{c}\text { Butterfly } \\
\text { Conservation (BC) }\end{array}$ & 2015-2019 \\
\hline $\begin{array}{c}\text { Small blue } \\
\text { butterfly }\end{array}$ & Cupido minimus & Chalk grassland & $\begin{array}{c}\text { Butterfly } \\
\text { Conservation (BC) }\end{array}$ & 2015-2019 \\
\hline Skylark & Alauda arvensis & Pasture/Arable & $\begin{array}{c}\text { Surrey Bird Club } \\
\text { (SBC) }\end{array}$ & $2010-2019$ \\
\hline $\begin{array}{c}\text { Hazel dormouse } \\
\text { Muscardinus } \\
\text { avellanarius }\end{array}$ & Hedgerow & $\begin{array}{c}\text { National Dormouse } \\
\text { Database (NDD) }\end{array}$ & $2008-2019$ \\
\hline Damselflies & $\begin{array}{c}\text { Anisoptera spp. } \\
\text { Zygoptera spp. }\end{array}$ & Inland water & $\begin{array}{c}\text { British Dragonfly } \\
\text { Society (BDS) }\end{array}$ & $2010-2019$ \\
\hline
\end{tabular}

\subsection{Resources for Very High Resolution (VHR) Satellite Imagery (Research for Step 3)}

We used VHR Multispectral (MS) and Panchromatic (PAN) data from 3 different satellite sources, DMC3, Superview, and Komsat 3/3A, purchased from Earth-i, for performing the habitat suitability assessments and the associated automated classification maps. The description of the satellites' camera mode, spectral and spatial resolutions, and the acquisition date are given in Table 2 . These satellite images were requested to be between spring and late summer when most tree crowns were leafy and crops had just been harvested; thus, we could discern different patterns, shapes, and textures to understand the landscape and habitat requirements of the selected species. As time-series images of the same location from 2016 until 2020 were available, we could also analyse for habitat change.

Table 2. VHR satellite data characteristics.

\begin{tabular}{|c|c|c|c|c|}
\hline $\begin{array}{l}\text { Satellite } \\
\text { Name }\end{array}$ & Camera Modes & $\begin{array}{l}\text { Spatial Resolution } \\
\text { and Bands }\end{array}$ & $\begin{array}{c}\text { Date of } \\
\text { Acquisition }\end{array}$ & Sites Covered \\
\hline \multirow{7}{*}{ DMC3 } & \multirow{7}{*}{ MS and PAN } & \multirow{7}{*}{$\begin{array}{l}\mathrm{MS}=4 \mathrm{~m} \text { (blue, } \\
\text { green, red, NIR) } \\
\text { PAN = } 1 \mathrm{~m}\end{array}$} & 6 May 2016 & Site 2 and 3 \\
\hline & & & 12 August 2016 & Site 1 \\
\hline & & & 6 May 2018 & Site 2 and 3 \\
\hline & & & 30 June 2018 & Site 1 \\
\hline & & & 20 April 2019 & Site 2 and 3 \\
\hline & & & 29 August 2019 & Site 1 \\
\hline & & & 25 June 2020 & Site 1 \\
\hline \multirow{3}{*}{ Superview-1 } & \multirow{3}{*}{ MS and PAN } & \multirow{3}{*}{$\begin{array}{l}\mathrm{MS}=2 \mathrm{~m} \text { (blue, } \\
\text { green, red, NIR) } \\
\text { PAN }=0.5 \mathrm{~m}\end{array}$} & 5 July 2017 & Site 2 and 3 \\
\hline & & & 19 May 2018 & Site 1 \\
\hline & & & 15 July 2018 & Site 1 \\
\hline \multirow{2}{*}{ Komsat-3 } & \multirow{2}{*}{ MS and PAN } & \multirow{2}{*}{$\begin{array}{l}\mathrm{MS}=2.8 \mathrm{~m} \text { (blue, } \\
\text { green, red, NIR) } \\
\text { PAN }=0.7 \mathrm{~m}\end{array}$} & 20 April 2018 & Site 1 \\
\hline & & & 6 May 2020 & Site 2 and 3 \\
\hline
\end{tabular}




\subsection{Analysis}

The following presents the analytical methods applied in each of the three research Steps summarised in Figure 1.

2.4.1. Step 1-Expert Knowledge Elicitation on the Habitat and Food Requirements of the Species

Expert knowledge was obtained from ecologists from the Surrey Wildlife Trust and Butterfly Conservation and from literature review to understand the relationship between the selected species and their habitat and food requirements in the SH-AONB. Likewise, the expert consultations guided us also in the selection of the five species, which play a role as indicators of an appropriate and healthy habitat both for themselves and in supporting the wider ecosystem and maintaining its balance [94]. In consequence, the presence of such key species indicates a healthy habitat, its good management providing food and shelter for these species and suggesting thriving biodiversity. These represent an indirect contribution to other 'public goods' such as improvements in carbon storage, improving clean air and water quality, enhancing the landscape, mitigating climate change, and promoting heritage engagement with the environment, well-being, and protection from environmental hazards.

The five species and their requirements are presented in Supplementary Materials Table S2 [95-103].

\subsubsection{Step 2-Habitat Suitability and Connectivity Modelling Using Existing EO and Other Resources}

The ecological information on the basic needs of these species for food, habitat type, dispersal movement, and breeding (Table S3 [98,102,103]) was integrated with variables such as land cover, crop type, footpaths, topographical parameters, watercourses, settlements, etc., that could be observed in sufficient detail from the EO. These EO-observable variables played an equal role in evaluating the habitat suitability and its connectivity for the studied species. This habitat suitability evaluation process was applied both at the level of the three intensive study sites and also at the whole SH-AONB area level.

The following workflow was performed for the EO-based habitat suitability and connectivity modelling:

(a) Choose the environmental variables (factors) based on species habitat and food requirement

We used 6 different environmental variables, which can be placed into 3 categories including land cover [104], topography [105], and anthropogenic [106] (Table 3). In our modelling, we used land cover (UK CEH LCM2019), crop type (UK CEH Crop Type 2019only for Skylark), and chalk grassland (priority habitat inventory-only for modelling the Small Blue butterfly suitable habitat) as a means of habitat type, vegetation structure, and food availability. Land cover plays a role as a key variable in this analysis, and it was used to model all habitat suitability of the studied species. The anthropogenic variables selected in this study are footpaths and settlements (urban and suburban areas). These variables (depending on the species-habitat relationship) are likely to affect the connectivity within the habitats. For instance, the settlements vector layer was used as a pressure factor for Skylark nesting habitat; thus, we created a $100 \mathrm{~m}$ buffer around the settlement polygons. However, well-managed footpaths and bridleways that cross the broadleaved woodland can be a positive aspect in maintaining a Silver-washed fritillary butterfly population. Moreover, the topographic variable extracted from DEM was needed to ascertain the slope degree, which is an important factor in understanding the small blue butterfly's favoured habitat.

(b) Georeferenced species occurrence records

In this study, the occurrence records of the species were combined with (overlaid on) the results of habitat suitability analysis. This was considered as a further indicator for the 
presence of healthy and appropriate habitat, thus reinforcing the potential of a location as suitable for the species.

Table 3. Environmental variables used in developing habitat suitability model.

\begin{tabular}{cccc}
\hline \multirow{2}{*}{$\begin{array}{c}\text { Species } \\
\text { Silver-washed } \\
\text { fritillary butterfly }\end{array}$} & Environment Variables & Data Source & Variable Type \\
\cline { 2 - 4 } & $\begin{array}{c}\text { Habitat type } \\
\text { Broadleaved woodland } \\
\text { edge }\end{array}$ & UK CEH LCM2019 & Land cover \\
\cline { 2 - 4 } & $\begin{array}{c}\text { Footpaths through } \\
\text { broadleaved woodland }\end{array}$ & Open Street Map & Anthropogenic \\
\cline { 2 - 4 } Small blue butterfly & Habitat type & UK CEH LCM2019 & Land cover \\
\cline { 2 - 4 } & Chalk grassland & $\begin{array}{c}\text { Priority habitat } \\
\text { inventory (England) }\end{array}$ & Land cover \\
\cline { 2 - 4 } Skylark & Slope degree & DEM & Topographic \\
\cline { 2 - 4 } & Habitat type & UK CEH LCM2019 & Land cover \\
\hline Hazel dormouse & Crop type & UK CEH Crops2019 & Land cover \\
\hline \multirow{2}{*}{$\begin{array}{c}\text { Settlements } \\
\text { Dragonflies and } \\
\text { Damselflies }\end{array}$} & Habitat type & UK CEH LCM2019 & Anthropogenic \\
\cline { 2 - 4 } & $\begin{array}{c}\text { Habitat type } \\
\text { Slow-flowing } \\
\text { brooks, stream, rivulets, } \\
\text { and rills) }\end{array}$ & UK CEH LCM2019 & Land cover \\
\hline
\end{tabular}

\section{(a) ArcMap tools}

The datasets presented in Section 3, UK CEH LCM2019, UK CEH Crop type 2019, species occurrence georeferenced records, OS Open Rivers, Open Street map footpaths, and slope derived from DEM, were processed through a wide variety of tools in ArcGIS 10.6.1 (e.g., Extract, Buffer, Reclassify, etc.) to design the habitat suitability and connectivity of the monitored species. A detailed workflow is presented in Supplementary Materials Table S4.

(b) Scoring system (from 1 to 5) based on species habitat and food requirement

Table 4 explains the rationale behind the scoring system. Scores were assigned from 1 to 5 , where 1 is attributed to the least suitable habitat and 5 represents the most suitable habitat of a species.

Table 4. Habitat scoring system and rationale.

\begin{tabular}{ccc}
\hline Score & Habitat Suitability & Rationale \\
\hline 1 & Least suitable/unsuitable & Species cannot survive due to the lack of food \\
\hline 2 & Low suitability & $\begin{array}{c}\text { Species cannot cross through that area (depending } \\
\text { on species and the area size) due to the lack of } \\
\text { food. }\end{array}$ \\
\hline 4 & Moderately suitable habitat & $\begin{array}{c}\text { Species may travel through to reach other more } \\
\text { suitable areas, but it is unlikely to find food } \\
\text { sources. }\end{array}$ \\
\hline 5 & Suitable habitat & $\begin{array}{c}\text { It may be used occasionally but dependant on } \\
\text { other factors such as food availability or ideal } \\
\text { requirements to sustain a breeding population. }\end{array}$ \\
\hline
\end{tabular}




\subsubsection{Step 3-Habitat Assessment Approach and Contribution of VHR EO Data}

This step explored the use of VHR EO data, via visual interpretation (manual) and supervised image classification (automated). This VHR-based habitat assessment was performed at the three intensive study sites by combining:

- $\quad$ prior expert knowledge about the studied species

- $\quad$ either or both visual interpretation and automated classification of features of the VHR imagery

- $\quad$ species occurrence georeferenced records and OS Open Rivers (only for Dragonfly and Damselfly species).

The advantage of very high spatial resolution (between $0.7-4 \mathrm{~m}$ in this study) was to unlock rich information for the species by distinguishing pattern, shape, texture, shadows, and colours (see Figure S1) and to reveal observable detail about the habitat(s) such as field boundary characteristics (e.g., hedgerows and field margins), agricultural management practices, ditches, woodland canopy structure, type of woodlands, continuity of the habitat over time, the interconnectedness of different types of habitats, etc. Patterns, shapes, texture, shadows, and colours were discriminated in "true colour" bands and translated into key features (see Table S5 [107] and Figure S1).

\section{Results}

The outcomes of the Step 2 (habitat suitability and connectivity) and Step 3 (habitat assessment via visual interpretation and supervised classification methods) for the five species are presented in this section. The information from Step 1, expert knowledge elicitation (complemented with appropriate records), is not presented because it is embedded as underpinning knowledge for the other two steps (see Table S2 [95-103] and Table S3 $[98,102,103])$.

\subsection{Step 2-Habitat Suitability and Connectivity Analysis}

We designed our representation and mapping of the habitat suitability and connectivity for our chosen species in the SH-AONB and our three intensive study sites using a $1-5$ scoring system $(1=$ least suitable, $5=$ highly suitable, see Table 4$)$. This representation for each species was derived from the Step 1 expert knowledge elicitation of the habitat requirements (e.g., type, structure, and food requirements, see Table S1 [56,82] and Table S3 $[98,102,103])$ integrated with the readily available datasets and resources (e.g., UK CEH LCM2019, UK CEH Crop, DEM, Priority Habitat Inventory, OS Open Rivers, and Open Street Map).

\subsubsection{Silver-Washed Fritillary (SWF) Butterfly}

Figure 5 shows the suitable habitats of SWF butterflies in SH-AONB and the three intensive study sites. As the most suitable habitat (score 5) that can sustain an SWF population is placed in mixed deciduous woodland with sunny, flowery rides, and glades, and its edges, heather, and scrub, we included a $20 \mathrm{~m}$ buffer alongside footpaths that cross broadleaved woodlands and a $20 \mathrm{~m}$ buffer edge of the broadleaved forests. In addition, a score of 5 was assigned to the heather and heather grassland land cover classes. Scores of 4 and 3 were assigned to broadleaved woodland and grassland respectively, as the SWF butterfly is a powerful flier, albeit restricted to areas of Viola flower presence which grows at the margins of broadleaved, open, and sunny grassland and heathland. Scores of 2 and 1 were assigned to Coniferous woodland and Arable, Freshwater, and Inland rock, respectively, as these habitats are poor for this species due to the lack of food or host for their eggs. In terms of habitat connectivity, a positive linking of the available favourable habitat can be observed at our three intensive study sites. The potential benefits of higher resolution at the local scale than what is available in this Step 2 evaluation would be to enable improved understanding of the canopy openness and the effects of management at woodland edges and in hedgerows (as a key habitat for understanding connectivity). This is explored further in Section 3.2.1. In addition, at the SH-AONB scale, we can observe 
the availability of many areas of suitable habitats that can support this species. However, the best areas are somewhat 'patchy' in distribution, with some isolation of one area from another.

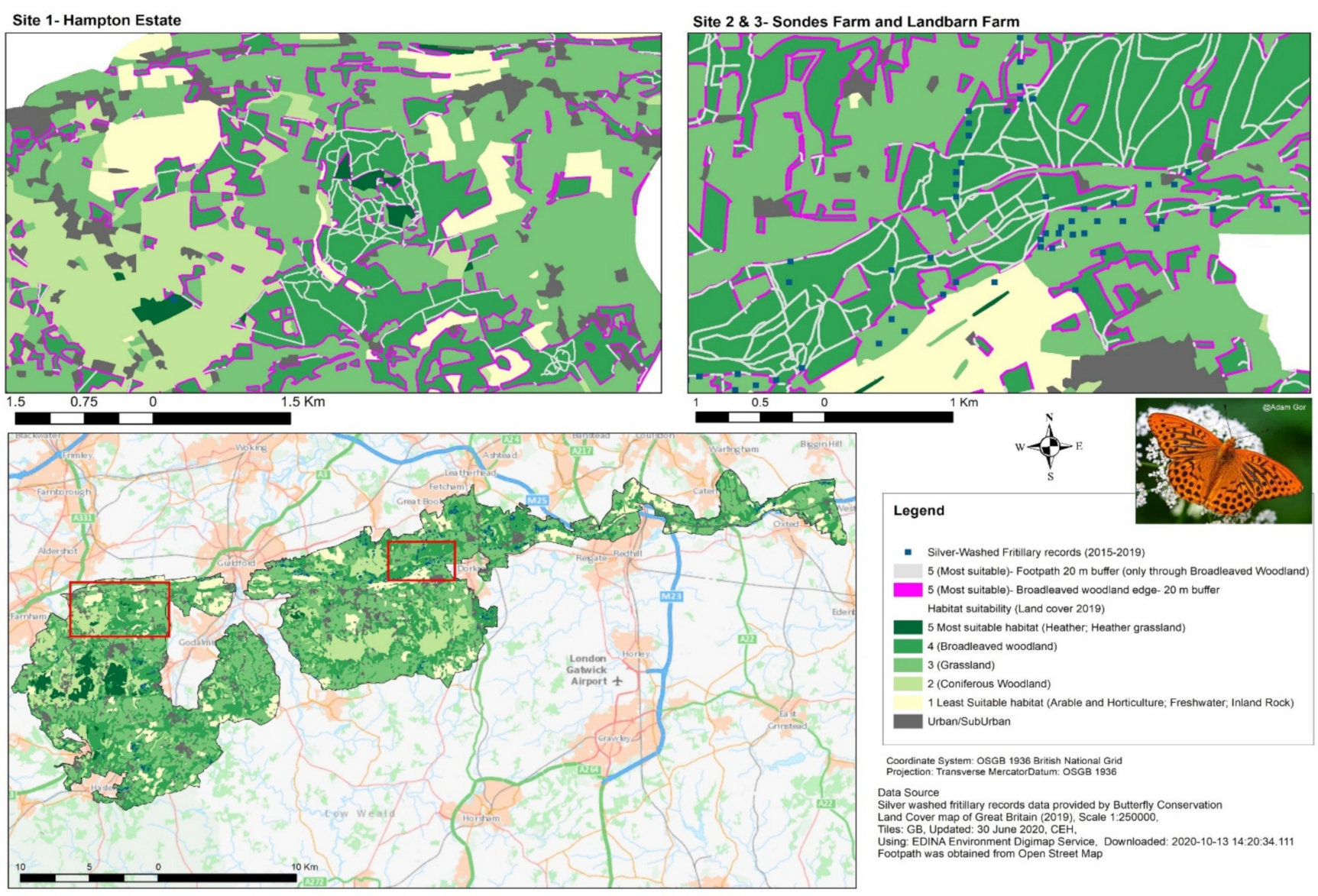

Figure 5. Silver-washed fritillary butterfly-Step 2 habitat suitability assessment in the SH-AONB and the three intensive study sites (red boxes).

\subsubsection{Small Blue (SB) Butterfly}

Figure 6 presents the suitable habitats for the SB butterfly, based on two environment variables: slope degree (Maps 1 and 2) and land-cover classes (Map 3). In addition, it overlays the records of SB butterfly from 2015 to 2019 which can indirectly confirm the presence of the Kidney Vetch plant (as this is only source of food for the caterpillars). It can be observed in both approaches (Maps 1 and Map 3) that most of the SB butterfly occurrence has been recorded across areas of chalk grassland (with a high slope degree), heather, and improved grassland.

In Map 3, the land-cover classes are classified based on our scoring system and the species habitat requirements. Therefore, at this Step 2 level, it is possible to observe several areas of potentially highly suitable habitat (score 4 and 5) that may offer the best opportunities for additional habitat creation for the SB butterfly, e.g., by seeding of Kidney Vetch in autumn or winter. However, further detailed examination of these broad potential habitat locations to find fully optimal sites (e.g., scrub or sparse eroding vegetation with bare ground, calcareous sites such as old quarries, gravel pits, and disused railways) would be advantageous and could be accomplished by site visits or, potentially, via a higher spatial resolution of EO imagery. Likewise, Map 3 illustrates the existence of many scattered areas of suitable habitat which can lead to the isolation of SB populations. Hence, the map from this Step 2 level can be useful for designing the introduction or restoration of connections between colonies (e.g., by even quite small habitat creation interventions) as a vital aspect 
of the long-term conservation of this species. Due to its good dispersal movement potential (efficient and light wings), maintaining the existing and new habitats and continuity among them depends on the farming activities and agricultural practices such as avoiding overgrazing by the livestock and fertilizer spray drift (see Table S3 [98,102,103]).
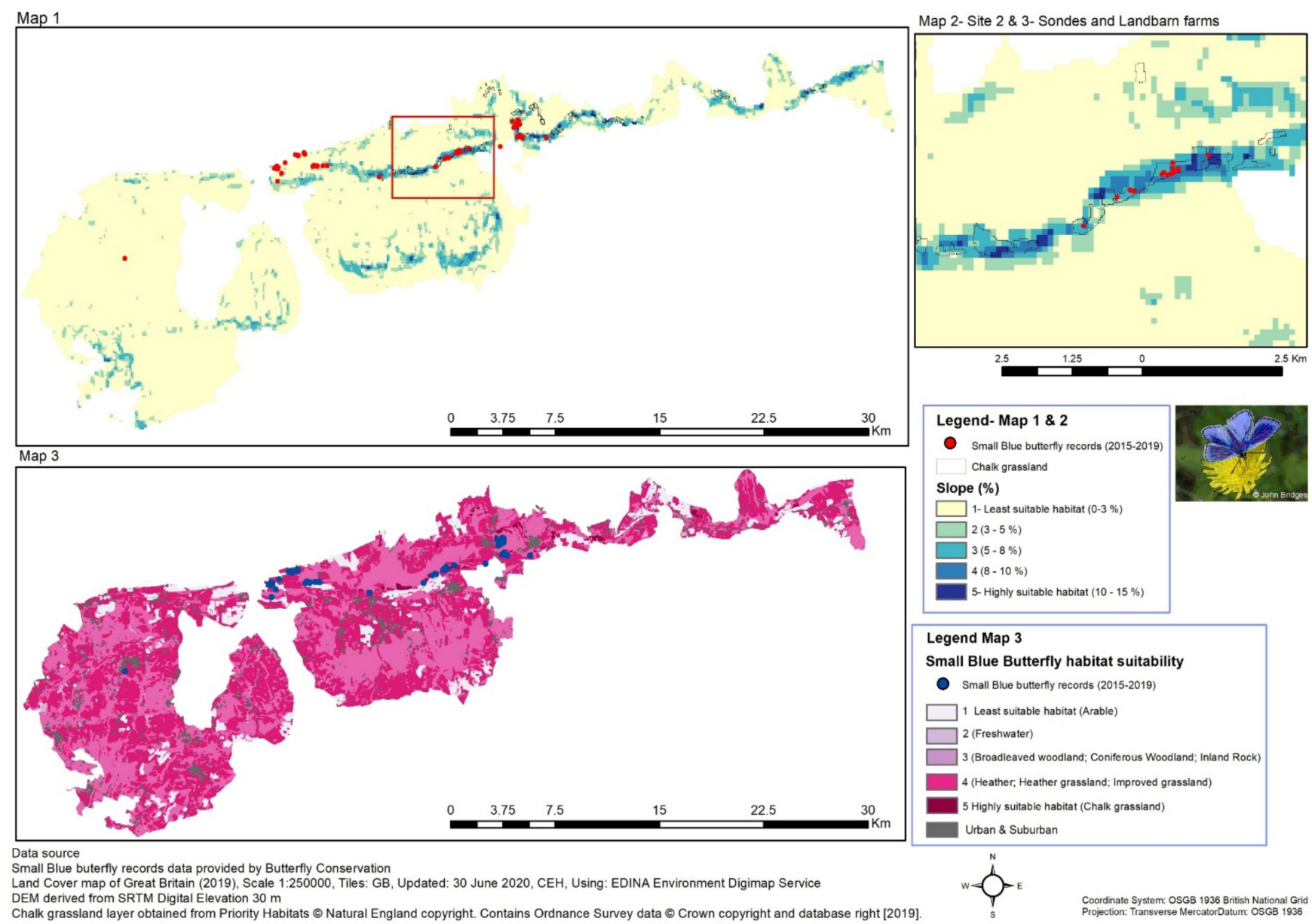

Small Blue buterfly records data provided by Butterfly Conservation
Land Cover map of Great Britain (2019), Scale 1:250000, Tiles: GB, Updated: 30 June 2020, CEH, Using: EDINA Environment Digimap Service

Chalk grassland layer obtained from Priority Habitats $\odot$ Natural England copyright. Contains Ordnance Survey data $\odot$ Crown copyright and database right [2019].

Figure 6. Small Blue butterfly-Step 2 habitat suitability assessment in the SH-AONB and the two intensive study sites.

\subsubsection{Skylark}

Skylarks select nesting sites at ground level with vegetation height about $20-50 \mathrm{~cm}$ to give easy access to the nest but also near to field margins that can provide food (insects). Certain crops such as spring and winter barley, spring wheat, and late-cut hay meadows are also ideal for nesting; however, nests are only successful if the field is not cut or grazed between early April and the end of May (see Table S3 [98,102,103]). Figure 7 shows suitable habitat for Skylark nesting in the SH-AONB and the three intensive study sites based on the CEH LCM2019 and CEH Crops 2019 classification and settlements. In addition, species record points between 2010 and 2019 can be observed across most of the suitable areas. However, the food requirement for this species cannot be assessed at this Step 2 resolution, and higher detail maps are required. Moreover, in terms of connectivity, Figure 7 illustrates that many sites ideal for nesting show quite high degrees of separation. Interpretation of the significance of this connectivity feature should include awareness that this species has a short-distance dispersal movement, and its home range has been noted as 1.08 ha [68]. 
Site 1- Hampton Estate

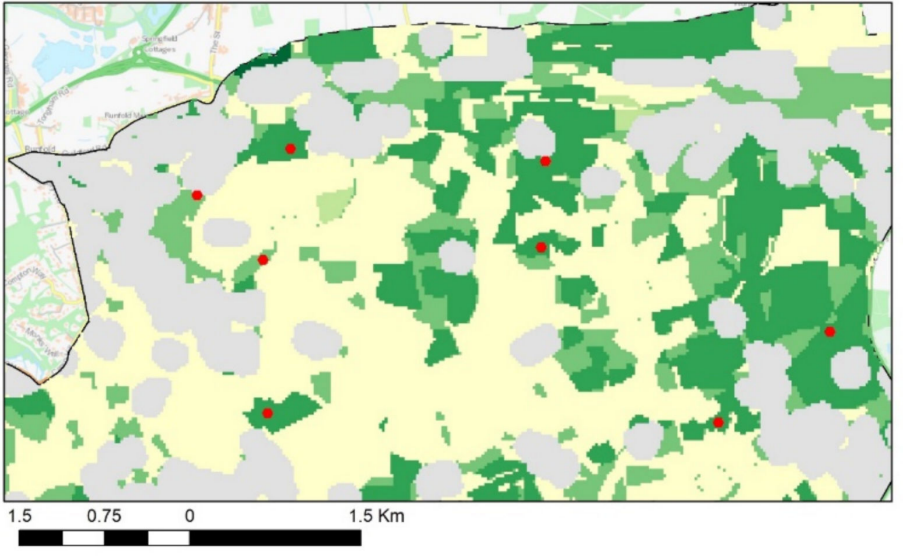

Site 2 \& 3- Sondes Farm and Landbarn Farm
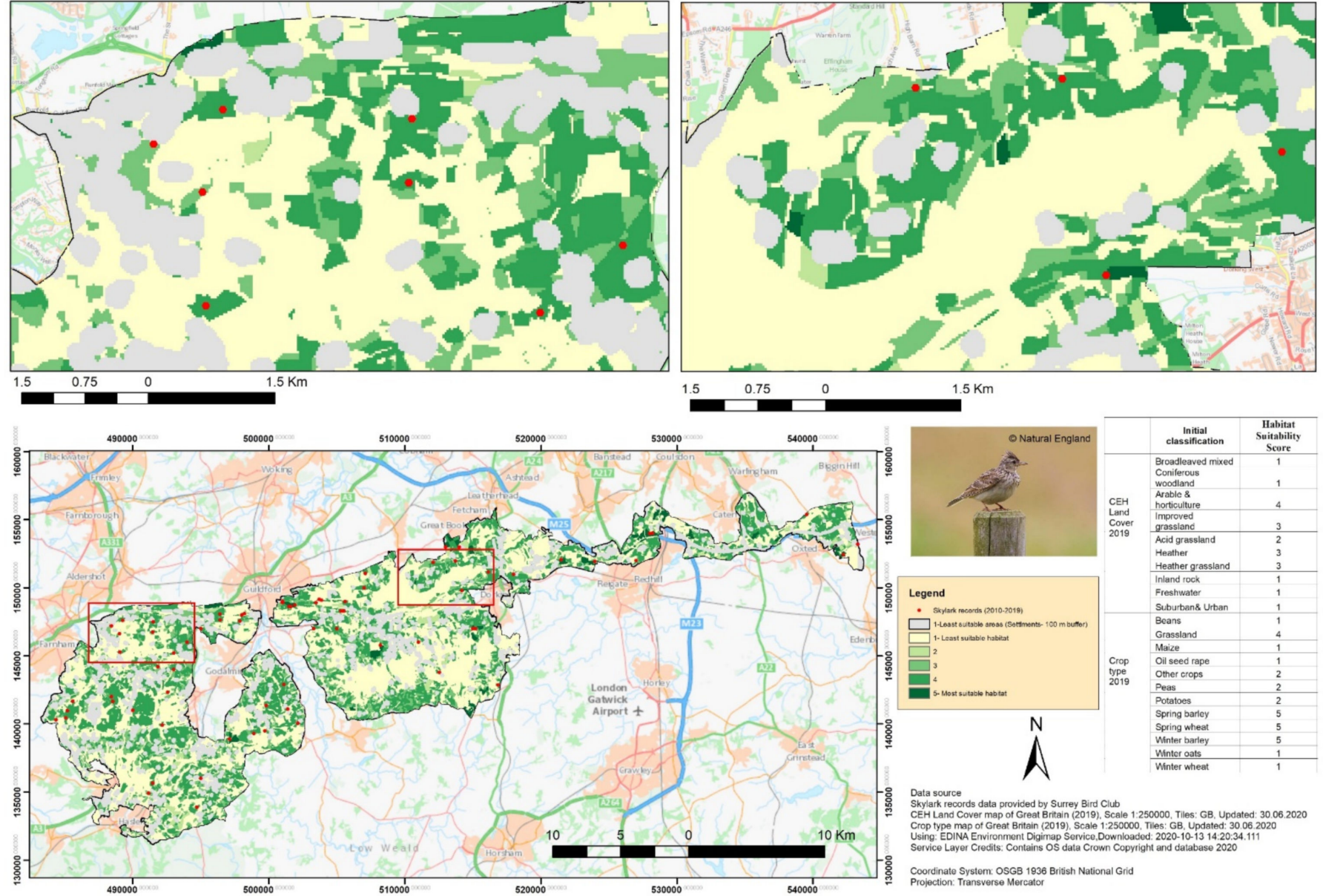

Figure 7. Skylark nesting—Step 2 habitat suitability assessment in the SH-AONB and the three intensive study sites.

\subsubsection{Hazel/Common Dormouse}

Habitat suitable for the Dormouse requires medium height $(5-10 \mathrm{~m})$ broadleaved woodland, scrub, heather, and tall hedgerows, which were the main driver for the five suitability classes identified based on the LCM2019 classes, as shown in Figure 8. A large amount of suitable habitat can be identified in the SH-AONB and the intensive study sites, but in some places, these are interrupted or fragmented by unfavourable habitats. It is notable that most of the dormouse occurrence records have been registered in those habitats that were assigned a score of 5 and 4 ; however, there are other suitable habitat areas in which dormouse occurrence has not been registered (e.g., across Site1).

\subsubsection{Dragonflies and Damselflies}

Figure 9 presents habitat suitability analysis for dragonflies and damselflies in Step 2. Despite a wide variety of these species (around 40) in the SH-AONB integrated into this approach, all rely mainly on clear and shallow waters, which can be part of a lake, pond, river, stream, ditch, or canal. Highly suitable habitats occur in Thursley National Reserve and its proximities, where most of the dragonflies and damselflies sightings have been recorded. As these species have preference for slow-flow watercourses, we created a $20 \mathrm{~m}$ buffer alongside all ditches, brooks, etc., as highly suitable habitat. Suburban and urban areas have not been included in the classification, although nature lovers may well have created small ponds in their gardens, and ditches and ponds can be present in municipal areas; hence, some occurrences have been recorded in suburban/urban sites. 


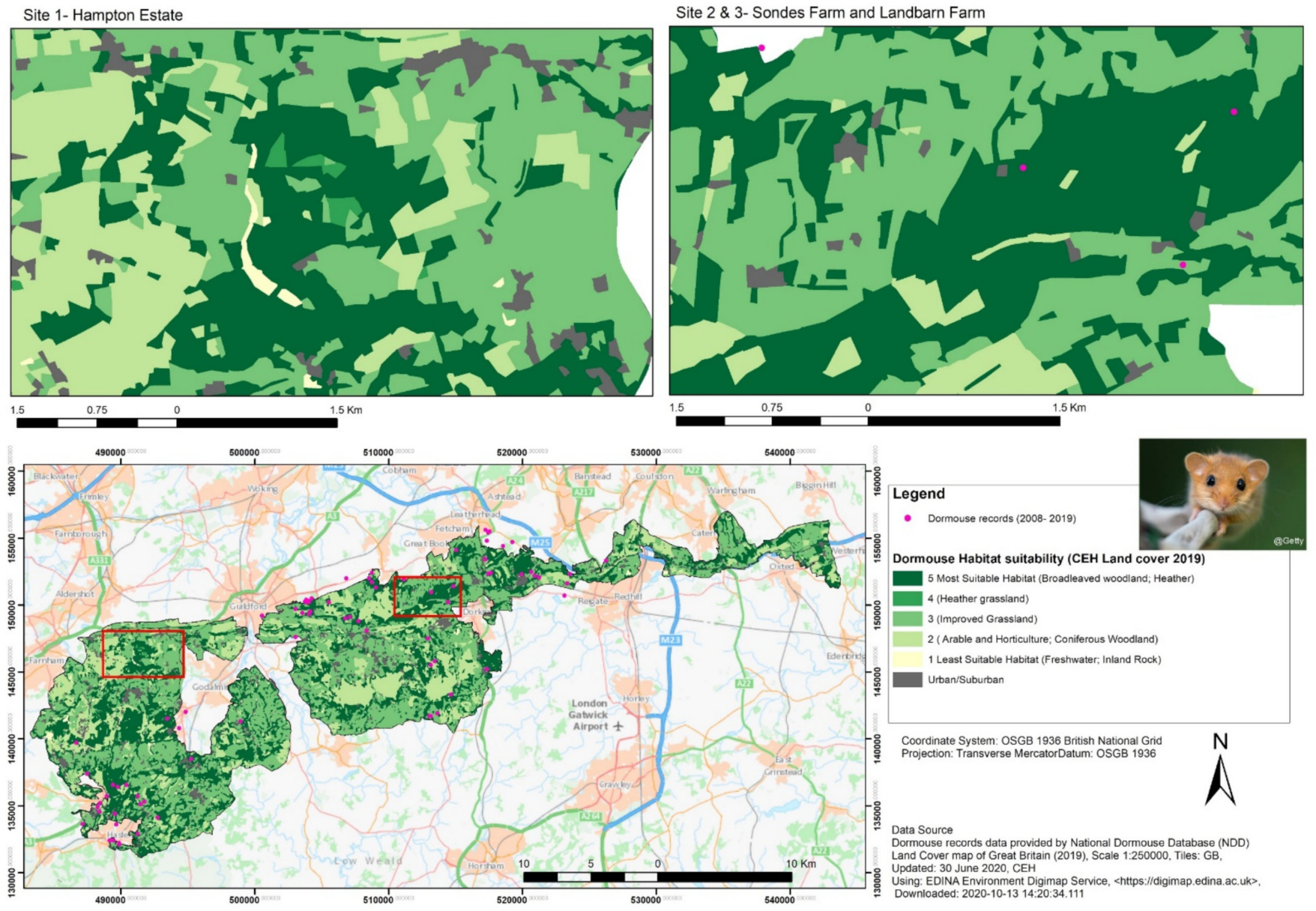

Figure 8. Dormouse-Step 2 habitat suitability assessment in the SH-AONB and the three intensive study sites.

\subsection{Step 3-Habitat Assessment Analysis with VHR Imagery}

The aim of the Step 3 approach was to investigate any additional value that VHR EO data can add to the understanding of available habitat for the five species from the Step 2 analysis. The analysis below is for the intensive study sites via the visual interpretation and the automated supervised image classification approaches. Interpretation of the VHR images by either approach applied the direct and indirect associations established between spectral bands (visible and PAN), textural, structural features, and plant diversity and habitat opportunities. The analysis also included examples of assessment over a period of time, opportunities to create/improve/extend suitable habitat, pressure factors, and dispersal movements for the species (see Table S3 [98,102,103]).

The VHR imagery-based analysis enabled observation of a larger range of speciesassociated habitat land-cover classes than in the LCM2019 set. These additional classes were canopy openness, scrub, hedgerows, water plants, trees shade, individual trees, and artificial features (tracks, pavement, etc). Visual interpretation of habitat assessment is time consuming, and particularly for larger areas, automated supervised image classification can play a very useful role in supporting efficient habitat quality and quantity assessment. 


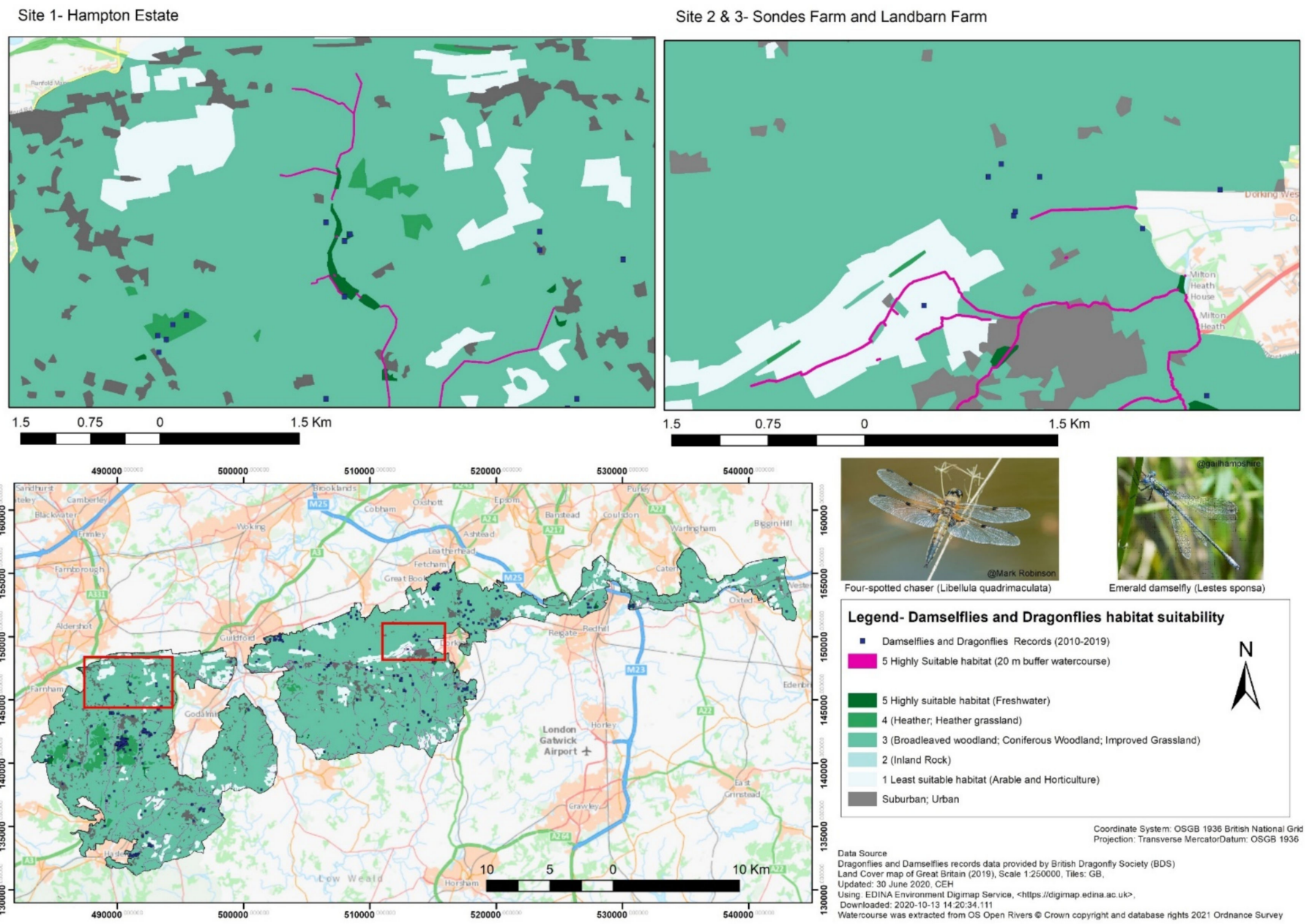

Figure 9. Dragonflies and damselflies-Step 2 habitat suitability assessment in the SH-AONB and the three intensive study sites.

The results of the VHR use are presented below in the same sequence of species as the results for Step 2. However, in this case, while noting habitat features relevant to the selected species our primary focus was on evaluating any 'additionality' that the VHR analysis can offer over and above that available from Step 2.

\subsubsection{Silver-Washed Fritillary Butterfly}

Figure 10 shows a well-vegetated area (Site 3) consisting of broadleaved and coniferous woodland, grazed grassland, maintained scrub patches, arable fields, ditches, hedges, etc. The broadleaved woodland exhibits several patches of open areas, glades and open rides that allow sunlight to come through, sunny and open woodland edges, and scattered scrub. These are all positive habitat features for this species and are revealed in finer detail than in the Step 2 results. The records of SWF sightings between 2015 and 2019 emphasise the presence of the species in such areas and also that such sightings coincide with walking pathways. The VHR images shows additional features such as other vegetation (providing additional shade) in places along such pathways across open grassland that also coincide with recorded sightings. In terms of assessment between July 2017 and May 2020, the detailed habitat features are mainly consistent between the two, indicating stability in the provision of appropriate habitat over this time series. Interestingly, there has been the removal of a small block of coniferous woodland over this time (see red circled area in Figure 10; shown as present 
in LCM2019 Figure 5 of Step 2) and the now open area observable in the 2020 imagery can provide additional habitat for this species.
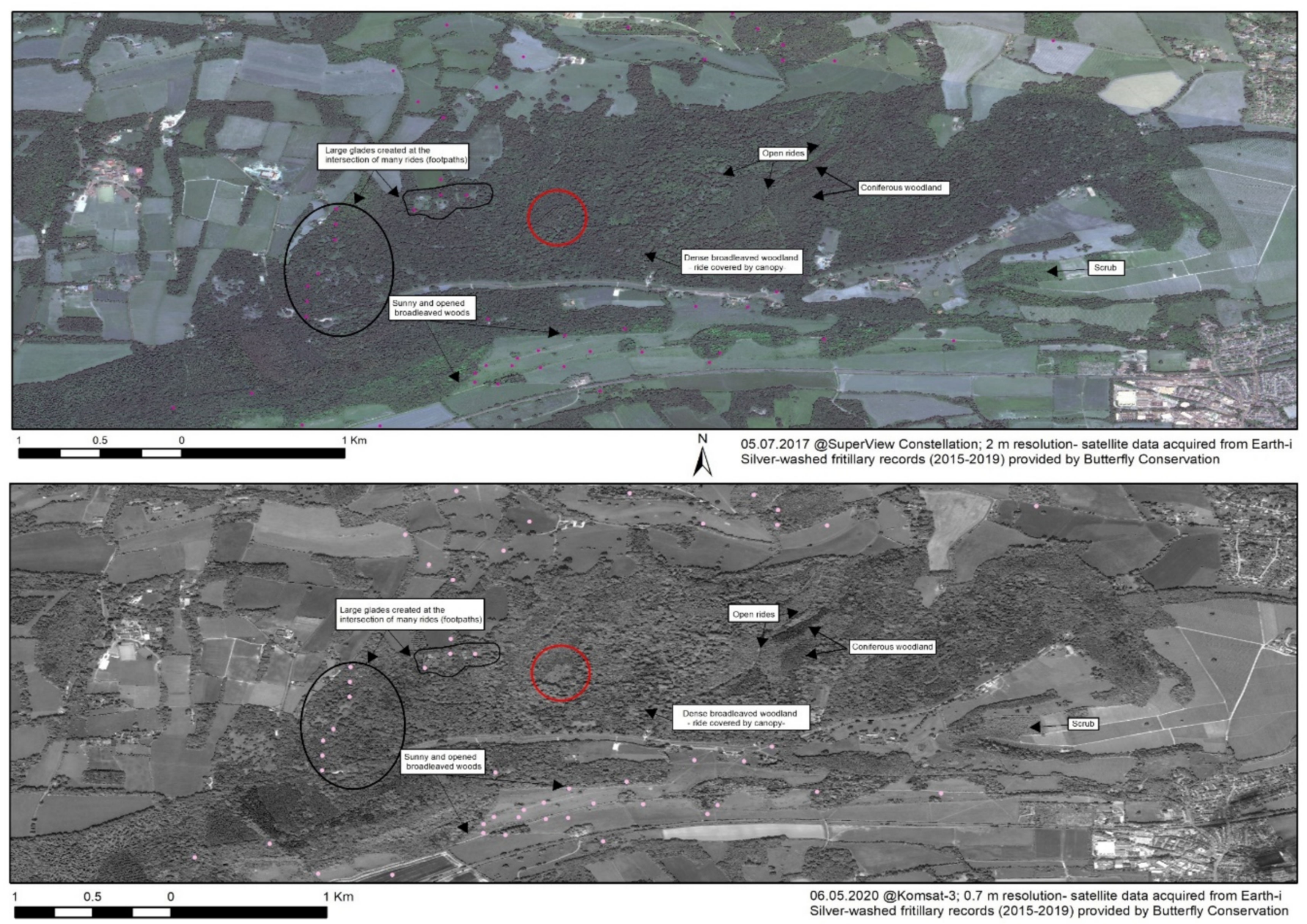

Figure 10. Silver-washed fritillary butterfly-Step 3 VHR habitat assessment, intensive study Site 3, visual interpretation (red circles indicate area of coniferous woodland removed between 2017 and 2020).

Figure 11 (Map 1) provides specific visual detail indicating highly desirable habitat for the SWF within the broadleaved woodland (canopy openness, glades and other spaces, open rides, etc.) that are absent from the Step 2 representation (Map 3). Similar detail is available for the grassland areas in which highly desirable scattered tree cover and associated shade is present. Map 2 shows that these highly desirable habitat features are also available from the supervised image classification indicating that they are tractable to automatic recognition and mapping. In this mapping, one conspicuous open ride is readily identified in the broadleaved woodland (red linear pattern in north-south orientation in Map 2) together with other areas of canopy openness and scattered trees, making location and calibration of these habitat features readily assessed. 

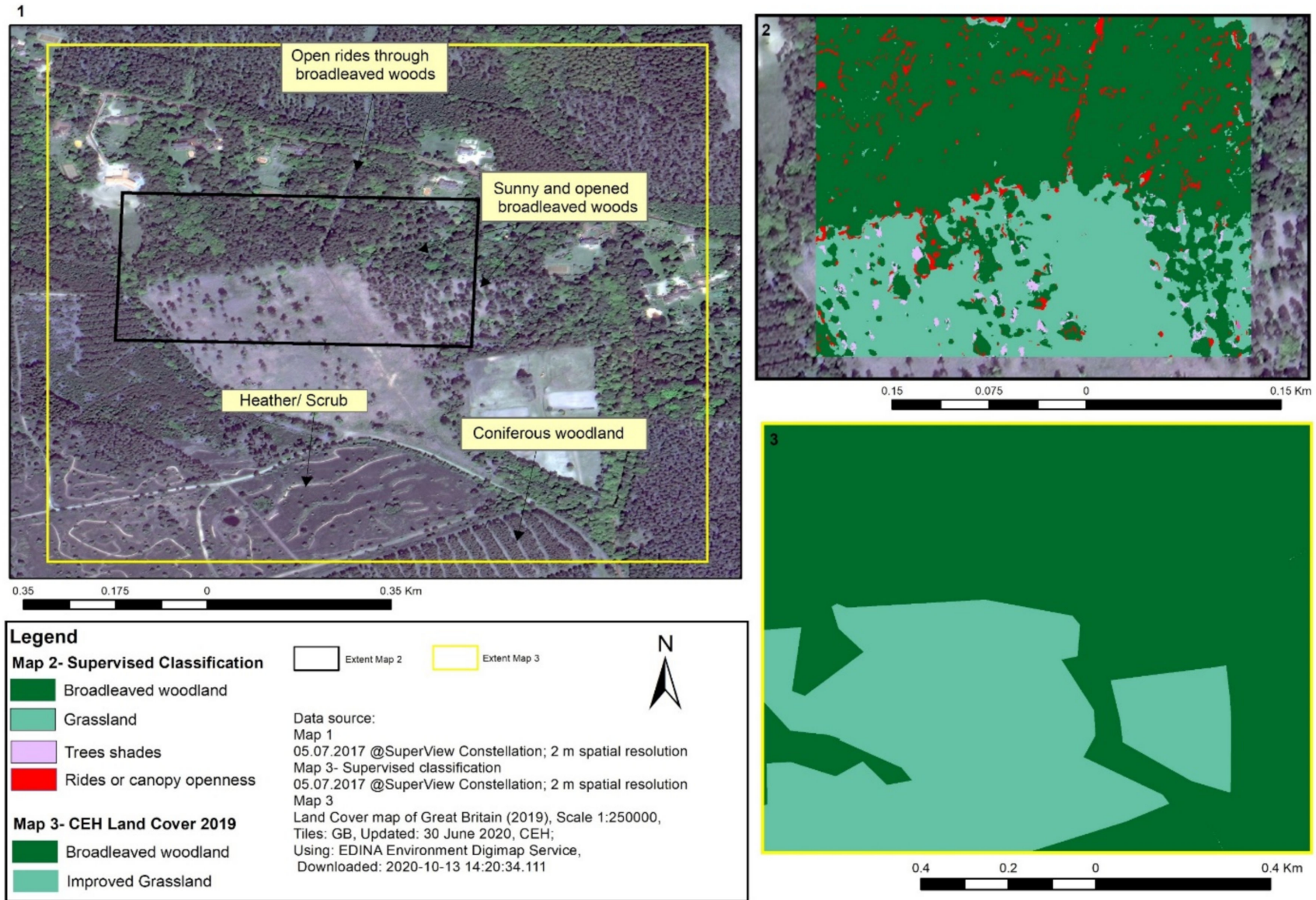

Figure 11. Silver-washed fritillary butterfly—Step 3 VHR habitat assessment, intensive study Site 1, visual interpretation (Map 1), supervised image classification (Map 2). Map 1 contains visual interpretation of $2 \mathrm{~m}$ resolution Superview satellite image; black box indicates the same area of view in Map 2; yellow box indicates the same area of view in Map 3; Map 3 shows the yellow box area of Map 1 overlaid with CEH LCM2019 broadleaved woodland and improved grassland land-cover classes from Step 2 (scored 4 and 5, respectively, as highly suitable habitat for the species).

\subsubsection{Small Blue Butterfly}

Figure 12 presents a time series of VHR (ranging from 0.7 to $2 \mathrm{~m}$ ) DMC3 and Superview images in PAN and MS (visible bands) from 2016 to 2020 to assess the consistency of the SB butterfly habitat provision over this time period. As the SB butterfly presence is strongly linked to the condition of Kidney Vetch flower, even though this cannot be identified directly by satellite images, patches of scrub, sunny open space, and some areas of ungrazed grassland are readily discerned (the quality of grassland can be differentiated — the light grey (PAN) and light green (MS) are those areas with grazed grassland: the dark grey and green is tall grass and scrub), and all these types of areas are positive for the Kidney Vetch. In addition, detailed assessment of the habitat observable from the VHR imagery over the 2016-2020 period provides evidence that the habitat has been stable and well maintained over this 5-year period, thus providing support for the SB population. 

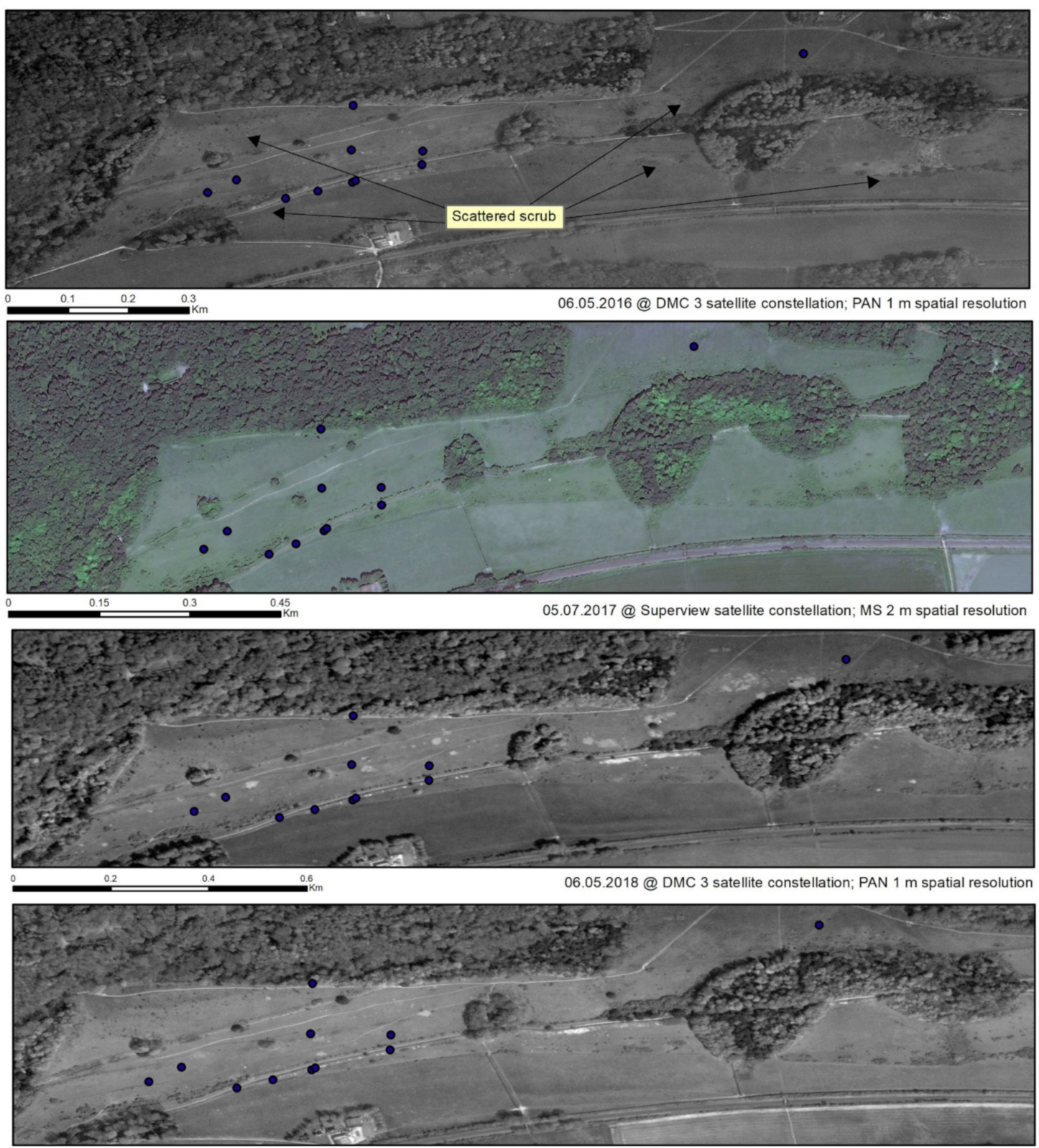

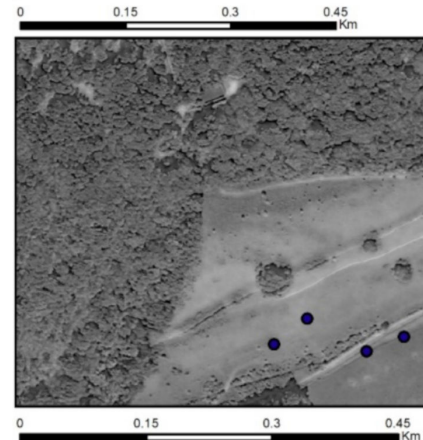

Legend

- Small Blue butterfly records (2015-2019) Data provided by Butterfly Conservation
20.04.2019@ DMC 3 satellite constellation; PAN 1 m spatial resolution

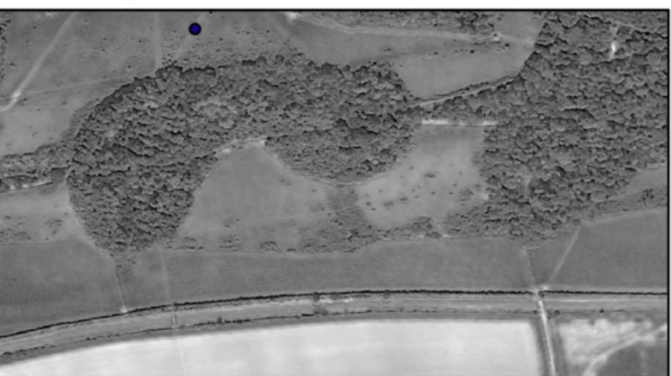

06.05.2020 @ Komsat-3 satellite constellation; PAN 0.7 m spatial resolution

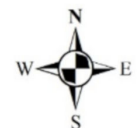

Coordinate System: GCS WGS 1984 Datum: WGS 1984 Units: Degree

Figure 12. Small blue butterfly—Step 3 VHR habitat assessment, intensive study Site 3, visual interpretation over time series. 
Figure 13 illustrates the use of VHR imagery for automated quantification of the habitat relevant for the SB butterfly in a $0.5 \mathrm{~km}^{2}$ area within Site 3. The histogram shows the percentage of different land-cover classes using supervised image classification in which the VHR imagery has provided much finer detail, thus obtaining the areas of scrub, unimproved grassland, and footpaths, classes that are not available via LCM2019 data. For example, the automated quantification shows that $13 \%$ of the selected area is scrub associated with $46 \%$ of open grassland, which together offer highly favoured habitat for the SB.
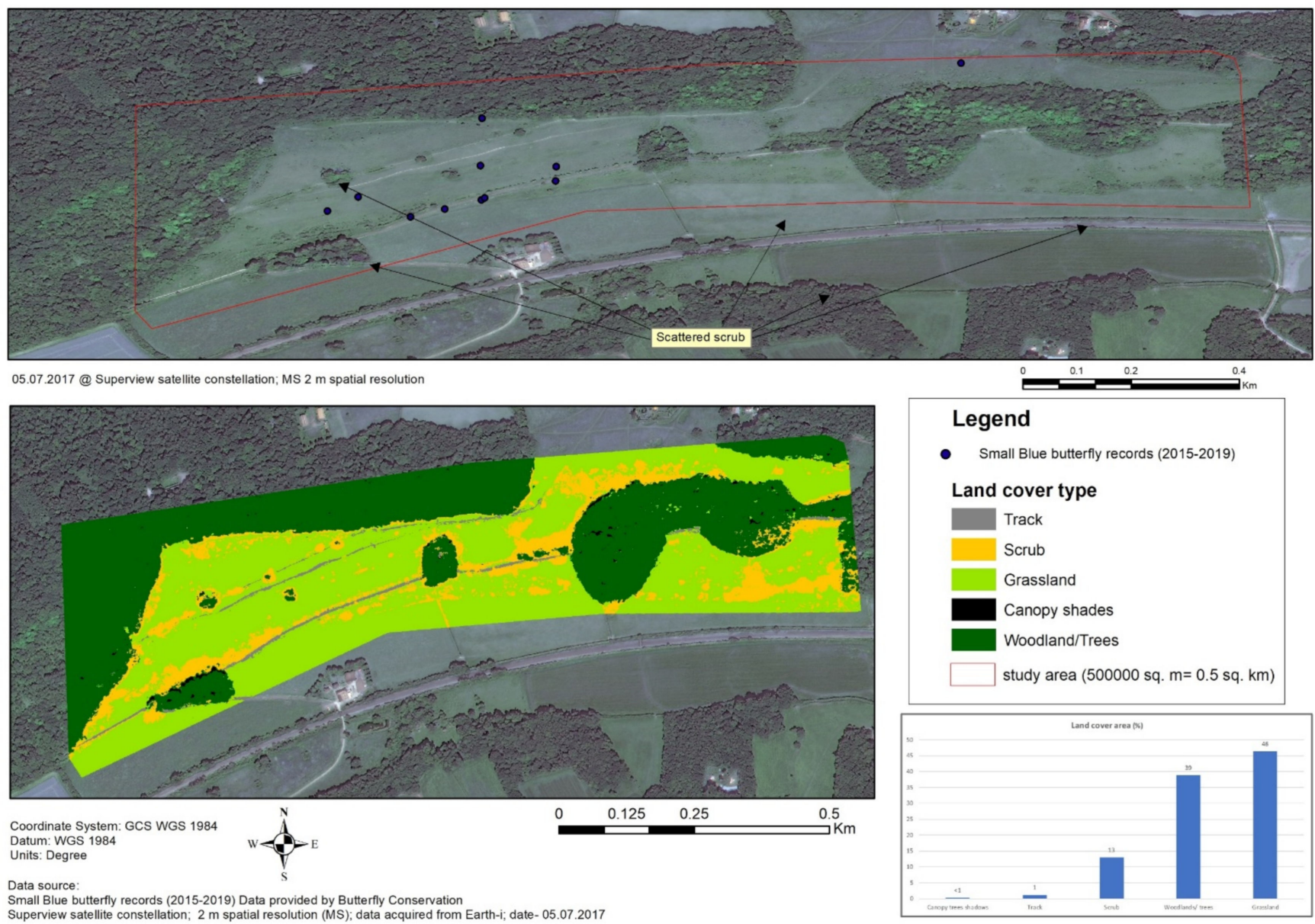

Figure 13. Small Blue butterfly—Step 3 VHR habitat assessment, intensive study Site 2, visual interpretation, supervised image classification with quantification.

\subsubsection{Skylark}

This bird can nest in silage fields (grazed pasture) if the field is not grazed between early April and the end of May. Figure 14 presents an example of monitoring such habitat suitable for Skylark nesting in four grass/silage fields at intensive study Site 1, by using VHR satellite images in mid-May and again in late-June 2018 and species sighting recorded in the same year. The fields are clearly uncut in May 2018, thus maintaining this habitat for Skylark nesting and rearing, and they are showing as cut (for silage) at the end of June 2018, after this important period for the Skylark. It is clear that the detail available from the VHR imagery is sufficient to assess the status of these fields (cut/uncut), and therefore, with appropriate overflies and image collection frequencies, VHR can be used readily to monitor the grass management in support of Skylark nesting habitat. We believe that the Skylark seen in 2018 was successfully maintained by the agricultural practices in place at that time. 

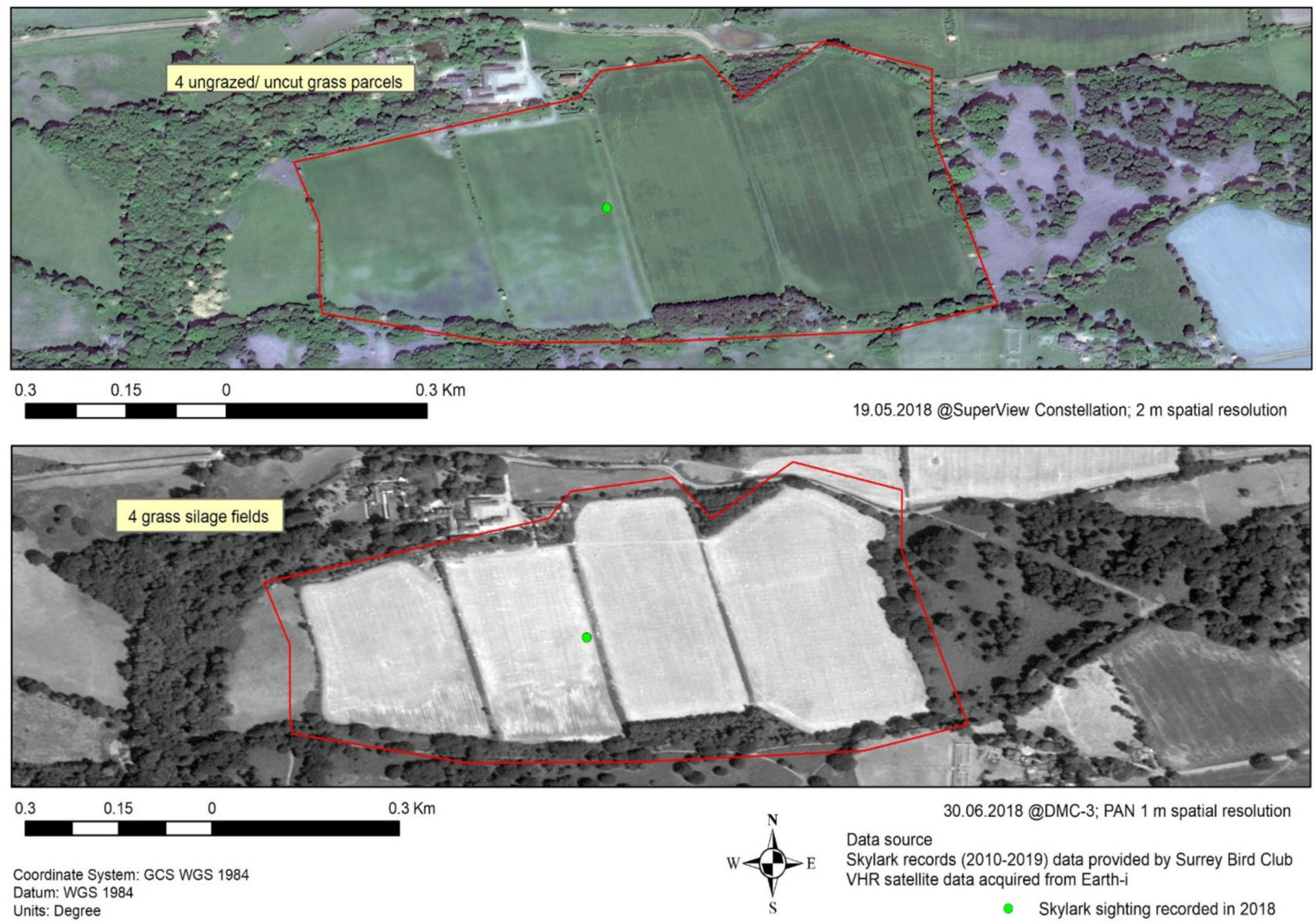

Figure 14. Skylark Nesting-Step 3 VHR habitat assessment, intensive study Site 1, visual interpretation.

Figure 15 shows a grass field at intensive study Site 2 in 2017 and 2020. This location is a suitable nesting habitat for Skylark (skylark recorded there in 2017). The VHR imagery (Map 1 Figure 15) shows the field with full grass cover in early-July 2017, indicating that it had not been cut during the Skylark breeding season. Furthermore, the grass margins alongside hedgerows (lighter green (Map 1) and lighter grey (Map 2) Figure 15) are clearly present with a width of $\sim 10 \mathrm{~m}$ in both 2017 and 2020. These two practices, grass cutting time and field margins, plus the presence of hedgerows and neighbouring woodland (supporting insect and seed diversity), play a crucial role for the Skylark by providing a good physical location, source of food, and materials for nesting.

\subsubsection{Dormouse}

Favoured habitat for this species is deciduous woodland (preferring yew, rowan, and hazel during ranging), hedgerows, and dense scrub. Figure 16 illustrates a well-connected network of favourable dormouse habitat. In terms of the habitat quality, the dormouse population recorded in 2017 had a suitable habitat in both 2017 and 2020, noted as (+) in Figure 16, due to the dense and wider hedges and young woodland (bright green or light grey). However, there are some gaps in hedgerows, noted as (-) in Figure 16, which could have a negative impact on the species dispersal. Farmers and land managers can restore and/or add to hedgerows and fill such gaps to better link existing habitat areas for improved foraging and dispersal for this species. 


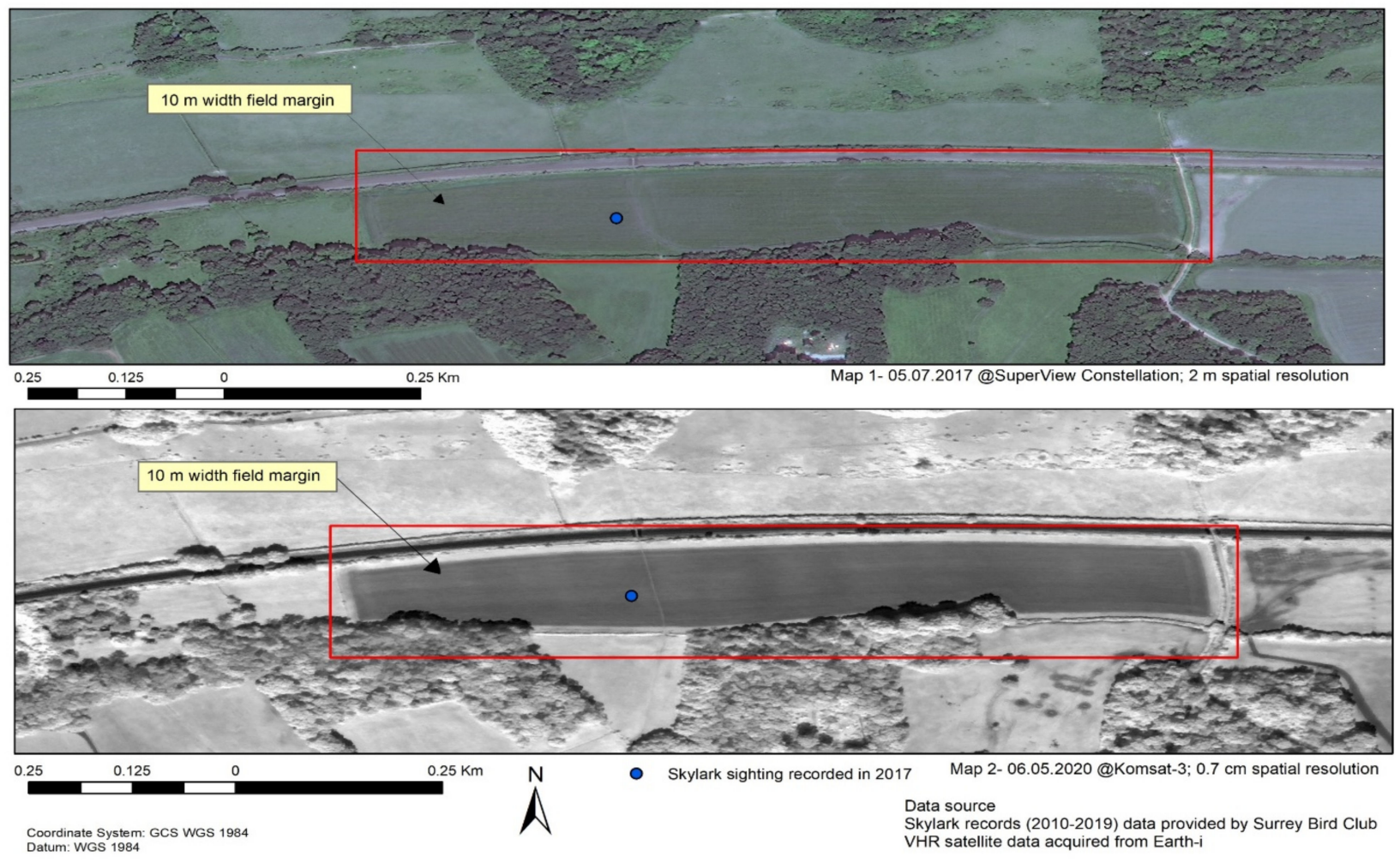

Figure 15. Skylark—Step 3 VHR habitat assessment, intensive study Site 1, visual interpretation.
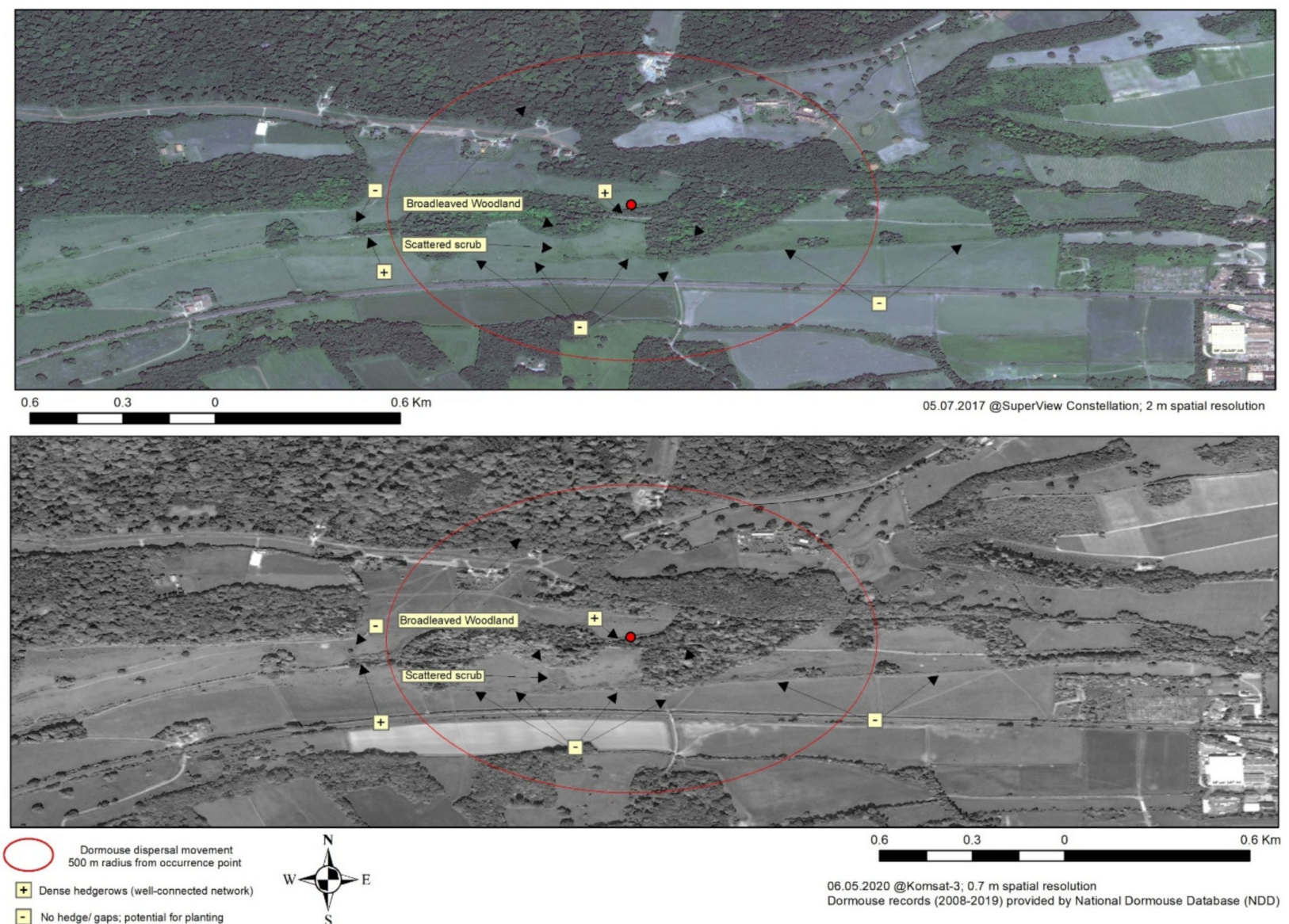

$\square$ No hedge/ gaps; potential for planting

Figure 16. Dormouse-Step 3 VHR habitat assessment, intensive study Sites 2 and 3, visual interpretation. 
Figure 17 shows a comparison of VHR imagery at $2 \mathrm{~m}$ resolution from SuperView (Maps 1 and 3, Figure 17) with the same area at $10 \mathrm{~m}$ resolution from of Sentinel 2 (as per LCM2019) (Map 2, Figure 17). As for the other species, the VHR imagery permits recognition and location of a much more granular classification and range of land-cover types for dormouse habitat assessment, e.g., scrub, patchy tree or tall shrub cover and shading as strong positive features. This is also tractable to automatic representation by the supervised image classification approach (Map 3, Figure 17).

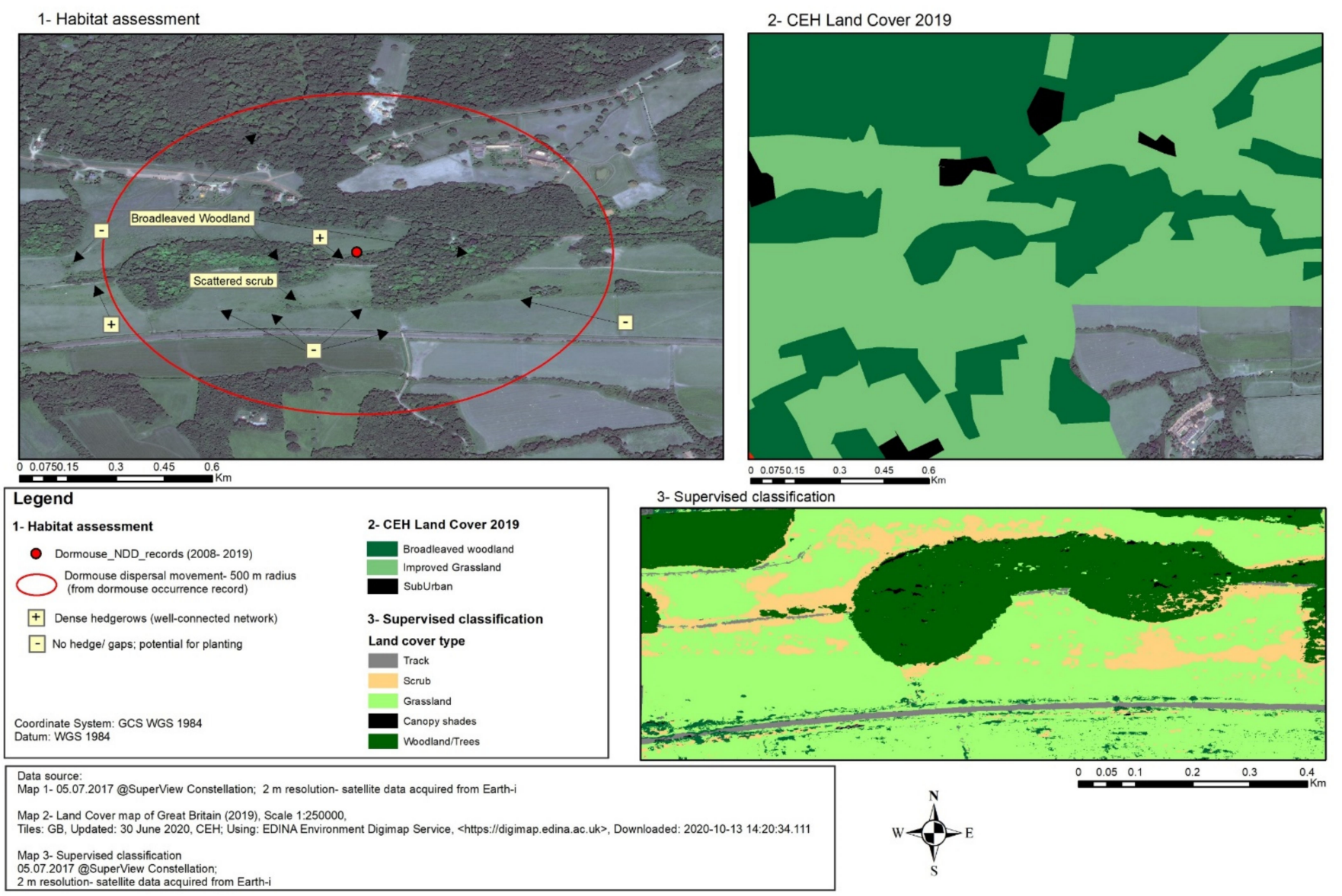

Figure 17. Dormouse-Step 3 VHR habitat assessment, intensive study Sites 2 and 3, visual interpretation and supervised image classification.

\subsubsection{Dragonflies and Damselflies}

Two of the main pressures on dragonflies and damselflies are (i) poor water quality from leaf litter, extensive growths of filamentous algae, water coloured green by planktonic algae, and nutrient inputs from agricultural practices, and (ii) livestock access to bankside vegetation. Therefore, Figure 18 shows that several variations in the habitat qualities for dragonflies and damselflies that can be distinguished through the use of VHR imagery for habitat assessment. The imagery from July 2017 and May 2020 permits recognition of positive habitat features such as thick bankside vegetation alongside ditches and a buffer zone of at least $10 \mathrm{~m}$ arounds the ponds that have not been affected by livestock both of which also provides reasonable protection against nutrients inputs from fertilisers, and from herbicides and pesticides. Negative features are also readily observed: for example, in 2017, the pond situated in the centre of the image (marked as red hexagon in Figure 18) was mostly covered by vegetation with extensive growth of aquatic plants. This is less 
apparent in 2020, which could be due to the low rainfall and higher temperature in the 2017 season.
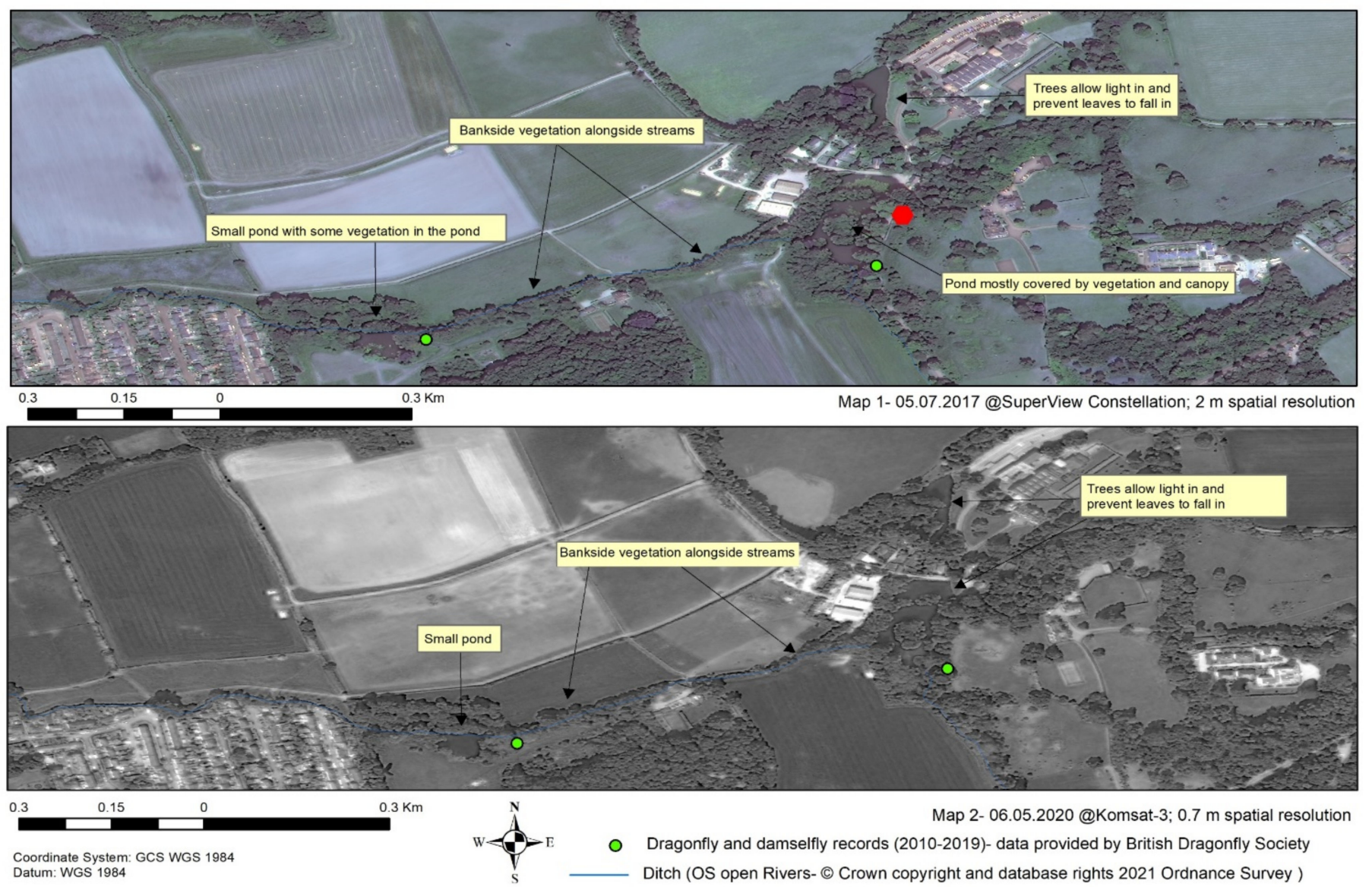

Figure 18. Dragonflies and damselflies—Step 3 VHR habitat assessment, intensive study Site 2, visual interpretation.

In Figure 19, the two VHR images from May 2018 and June 2020 present an array of open ponds in which habitat assessment features are easily recognised. The tree canopies are not overhanging, but in some areas, the light brown colouration of the water indicates the presence of sediments. This cloudiness could occur due to relatively shallow waters, if the pond is located on clay, or it can be caused by fish or ducks stirring up bottom sediments. Overall, it indicates a favourable and healthy habitat for dragonflies and damselflies, which concurs with the sighting records.

Many of the dragonfly and damselfly species in the SH-AONB have habitat preferences for clear ponds with open water surfaces and slow water flows (e.g., ditches). The upper two VHR images in Figure 20 shows a substantial amount of aquatic vegetation within the pond boundary with substantial tree cover surrounding. These conditions are not ideal habitat for these species. In comparison, the lower pair of images in Figure 20 show a high degree of openness of the water surface and an absence of aquatic plants or extensive shading and overhanging trees, indicating the bulk of the pond area provides high quality habitat for the species. The supervised image classification images in Figure 20 show that these main habitat features are tractable to automated assessment. 


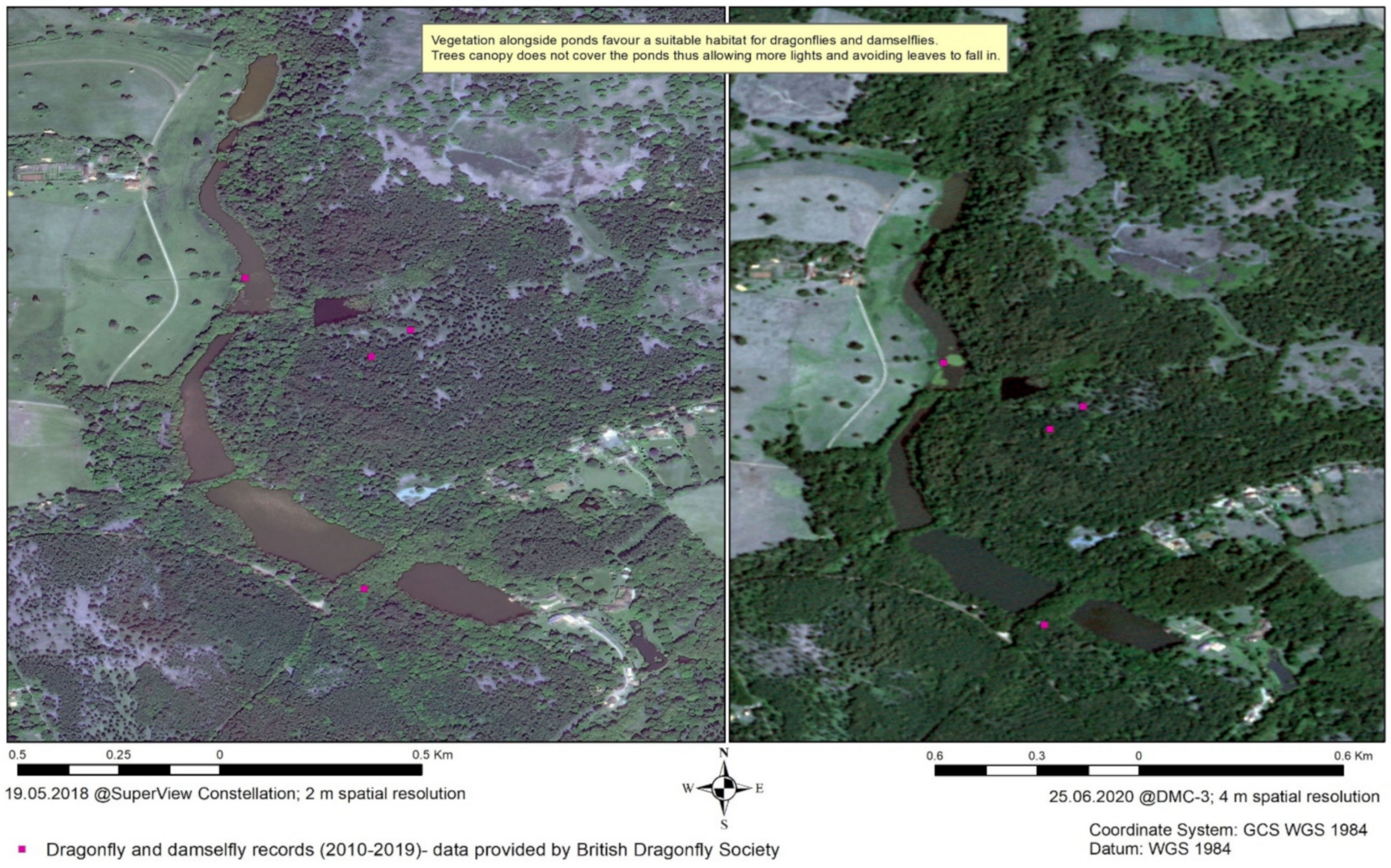

Figure 19. Dragonflies and damselflies—Step 3 VHR habitat assessment, intensive study Site 1, visual interpretation.
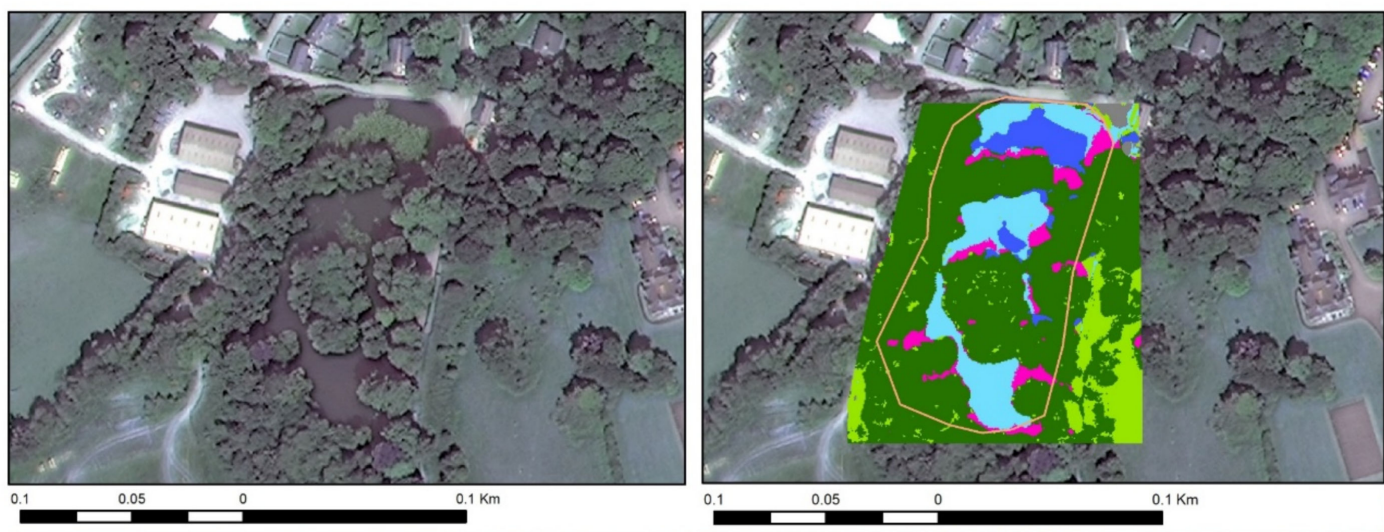

\section{Legend}

$\square$ Pond boundaries

Land cover

(unsupervised classification)

Grassland

$\square$ Freshwater

Manmade surface
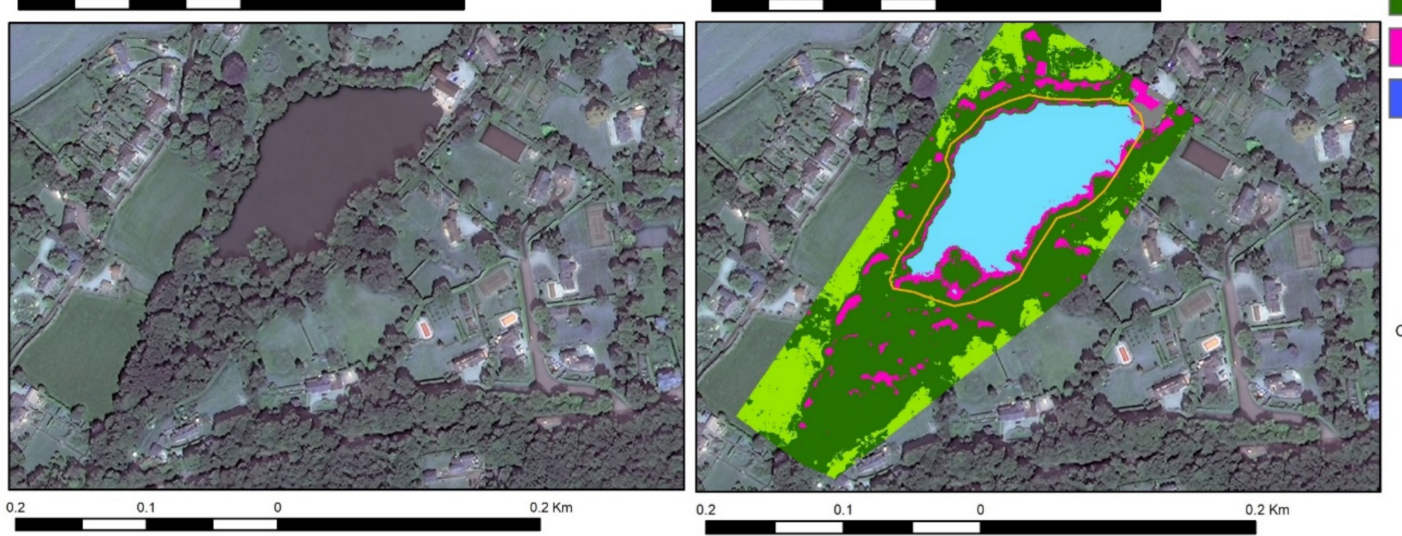

Trees

Trees' shadows

Water plants

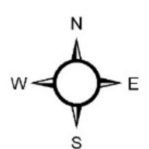

Coordonate System: GCS WGS 1984

Projection: Transverse Mercator

05.07.2017@SuperView 2 m spatial resolution

Figure 20. Dragonflies and damselflies-Step 3 VHR habitat assessment, intensive study Site 2 and surroundings, visual interpretation and supervised image classification. 
Detailed visual interpretation of the lower VHR imagery in Figure 20 indicates, however, some limitation in the precision of the automated supervised image classification in that the tapered, southwest part of the pond is classified as trees but is actually an overgrown part of the pond area. Close visual assessment shows that, while the main part of the pond, especially its more northern part, is very good habitat for these species, the lower southwest part exhibits a mix of freshwater (little open surface), trees, and other vegetation. A time series of imagery of his pond would enable interpretation of whether this condition of the pond's southwest part was due to the encroachment of vegetation into a previously open area of the pond or, conversely, if the cause was inundation of a previously vegetated area. This detail, readily observable in the VHR imagery here, provides a good demonstration of the value that VHR EO can bring, for example by indicating where management interventions can best be targeted to maintain or enhance available, high-quality habitat for particular species such as the dragonflies and damselflies in this case.

\section{Discussion}

This present study has examined the use of EO and geospatial datasets with a particular focus on the additional insight that VHR imagery (0.7-4 $\mathrm{m}$ resolution) can bring to the understanding of the availability, connectivity, and assessment at various scales of habitat suitable for five key species in the SH-AONB. Efforts to use the capabilities of EO for the purposes examined here depend crucially on combining knowledge on the habitat needs of the species in question (acquired from expert consultations and published sources) with that on EO technology and image interpretation. There are clearly important synergies here between these groups and use of the EO-derived data needed to have the input of experts who have in-depth knowledge of the ecology of the species. Similar image classifications have been accomplished in the literature [37]. The present research has provided several examples of the ways in which such a combination can be applied to habitat assessment.

EO-derived land-cover and land-use products have been used successfully for mapping and monitoring biodiversity and modelling species habitat suitability $[36,37,43,44,64,108]$ and for assessing ecosystem services $[108,109]$. Hence, at the scale of the whole SH-AONB, as well as for our three intensive study sites, the readily-available EO and geospatial datasets provide valuable resources enabling identification of the areas of broadly appropriate habitat for these species, albeit at a fairly 'coarse' level of resolution. In general terms, this provides a semiquantitative snapshot of potential habitat availability for the various species which may be particularly useful as a broad guide to the prevalence and location of the habitats across the whole SH-AONB. At the level of individual farms and similar landholdings, the readily available $\mathrm{EO}$ and geospatial datasets again provide the capability to broadly map suitable habitat at the individual property scale, e.g., several hectares. However, as is apparent from the habitat needs of these species outlined in Table S3 $[98,102,103]$ and in the detailed analyses, the high-level land classifications in the very useful LCM2019 data and similar/complementary resources only permit a quite general assessment of the availability and distribution of suitable habitat. A key question driving our research was whether information potentially available from the VHR satellite imagery could provide the level of detail that would enable a much more confident assessment of the quantity and quality of the habitat present for the given species. Further questions about such VHR imagery and its interpretation were related to whether such information would be relevant for habitat management and, potentially, for MRV systems for habitat provision under policies such as ELMs. These aspects form the basis of the discussion below.

VHR satellite data have proven efficient and accurate in assessing habitat quality [41,42]. The VHR data (0.7-4 m) used in Step 3 of this research allowed detailed analysis of image texture, patterns, colours, meanings, and identification and quantification of areas of scrub, hedges, field margins, different tree species types, etc. This was a considerable extension to the 'granularity' of habitat assessment over that available from the readily available resources analysed in Step 2 (which relied upon resolutions of $10 \mathrm{~m}$ or more and other 
geospatial datasets). Specifically, the benefits of using the VHR imagery as demonstrated in our results were a considerably extended capability to:

- Identify a wider range of landcover types relevant to the habitat preferences of the species than the range of classes in LCM2019. Notable amongst these was scrub (an aspect of preferred habitat of small blue butterfly, Silver-washed fritillary butterfly, and Hazel dormouse), 'patchiness' small open spaces in broadleaved woodland (Silver-washed fritillary butterfly), and recognition of small areas of single trees (Hazel dormouse, Silver-washed fritillary butterfly, and small blue butterfly).

- Assess qualitative differences within a given land class/habitat type-examples include the ability to resolve uncut and cut grassland as shown in the habitat assessment for the Skylark and, by inference, whether grassland areas are grazed or are tall/scrubby (the Kidney Vetch flower is associated with the latter, and the SB butterfly is dependent on this plant).

- Automate quantitative assessment of the habitat/land cover and automate the representation of the extended range of land-cover/habitat types via supervised image classification. This raises the potential to efficiently quantify at a finely resolved level (e.g., 1 to a few $\mathrm{m}$ ), the provision and location of suitable habitats for these, and most likely, many other species. Given the availability of suitable VHR image coverage, even quite large areas (up to $23 \mathrm{~km}^{2}$ ) are tractable to this finely resolved habitat assessment approach.

- Evaluate negative aspects of habitat provision such as discontinuities in valuable 'corridors' such as hedgerows (important avenues for migration and movement for wildlife and therefore a highly distinctive habitat) and diversity of 'qualities' within a given habitat type (such as ponds where features such as the quality of adjacent vegetation are also important).

- Evaluate habitat provision and quality efficiently and readily over time, offering valuable information for management decision making, e.g., urgency of intervention or responses and for efficient MRV for incentive schemes and policies.

- Assess habitat in 'non-traditional' urban and suburban areas by using the more finely resolved observation offered by VHR imagery to analyse the distribution and connectedness of relevant habitat types in such settings, and to support the nature recovery potential of private gardens, municipal and public spaces, and the built environment.

These benefits from the use of VHR imagery within this research are compelling. There are also a number of improvements and limitations that can be recognised. For example, species-habitat knowledge is a critical factor in the VHR interpretation as noted at the beginning of this discussion. It would have been advantageous to have had more extensive data, particularly for the occurrence records of the given species (and for those that they rely on for food). For instance, the SWF butterfly relies on the presence of Viola flowers and SB butterfly on the Kidney Vetch and having the records of the distribution and detailed preferences of these two plants would likely have allowed the creation of a more accurate habitat suitability analysis from VHR observations. Regarding access to VHR imagery, a more comprehensive time sequence for the imagery would have allowed unequivocal demonstration of land-use management directly supporting habitat provision. A good example of this was the full habitat assessment benefit that would have been possible if VHR imagery had been available for the precise harvesting time of silage grass cutting in relation to the Skylark. It is apparent from the levels of VHR resolution examined that the results presented here reflect habitat availability and its characteristics. The observations do not confirm if the species in question is actually present or not. The debate about whether the key metric for biodiversity conservation and enhancement should be (i) the availability of appropriate habitat (and its 'connectedness') or, (ii) whether it should be based strictly on species occurrence, lies outside the scope of this research. Therefore, it should be recognised clearly that the scope of the VHR imagery used here is at the level of 
habitat recognition and availability, rather than as a proof of species presence (although occurrence of the species was recorded where available in the image presentations).

The precision in time and resolution for assessing areas of land, as demonstrated in this research, clearly offer huge potential as primary evidence for the MRV of habitat and other benefits that are needed for the correct distribution of the incentives associated with ELM policy. Capitalising on this potential requires improved coverage in both time and area at these levels of resolution and at acceptable cost. EO data are becoming more and more widely used in governance and planning at all scales, and the demonstration of its cost-effectiveness in similar applications $[34,110]$ provides good reason to be optimistic that ongoing R\&D and applications development enable the near-term use of VHR imagery in MRV for ELM and related policy.

Finally, we wish to reiterate the usefulness of EO data to inform biodiversity conservation and environmental management as highlighted here and by remote sensing specialists and ecologists in recent years $[37,47,64,66]$. When EO is used in this field, it requires ongoing collaboration between ecologists and EO experts to develop a common, shared understanding about the relationship between the species selected and their habitats, terminology (e.g., regarding land-cover classes), guidance for understanding the opportunities to create/improve/extend suitable habitat for the species, and recognition of ecological and environmental pressures on the species. Such collaboration is essential to realising the outstanding potential for EO data to effectively support (i) ecologically informed environmental management decisions and (ii) the provision of habitat as a much-needed 'public good'.

\section{Conclusions}

We have drawn the following main conclusions from this research:

- Satellite spatial resolution is decisive in terms of assessing biodiversity and habitats. VHR data (at approximately 1-4 m) offers great potential for habitat suitability and connectivity assessment for the five wildlife species in this research and, most likely, for many more.

- Automated habitat suitability assessment using VHR imagery is feasible and provides valuable, ecologically meaningful information

- The expert insights of ecologists on the species-habitat relationships examined here provide key underpinning knowledge to enable use to be made of the potential of VHR satellite data for habitat assessment.

- VHR data and imagery offer great potential for use in habitat management at the scale of individual properties (farms, etc.) and at a whole-landscape scale. It provides an effective source of information of value for land management and environmental decision making and as potential evidence for the MRV relevant to ELM and similar policies.

Supplementary Materials: The following are available online at https://www.mdpi.com/article/ 10.3390/su13169105/s1, Table S1. UK CEH Land Cover 2019 classes description; Table S2. Habitat requirements of 5 studied species; Table S3. Species habitat requirement and opportunities to create/improve/extend suitable habitat for selected species; Table S4. Workflow of modelling the habitat suitability and connectivity; Table S5. Habitat assessment approach and contribution of VHR satellite imagery; and Figure S1. Examples of VHR satellite data.

Author Contributions: Conceptualization, A.A., R.J.M., S.M. and J.L.; methodology, A.A., R.J.M., S.M. and J.L.; software, A.A.; validation, A.A., R.J.M., S.M. and J.L.; formal analysis, A.A., investigation, A.A.; resources, A.A., S.M. and R.J.M.; data curation, A.A.; writing—original draft preparation, A.A.; writing-review and editing, A.A., S.M., R.J.M. and J.L., visualization, A.A.; supervision, S.M., R.J.M. and J.L., project administration, R.J.M.; funding acquisition, S.M., R.J.M. and J.L. All authors have read and agreed to the published version of the manuscript.

Funding: This research was part-funded by Natural Environment Research Council (NERC) SCENARIO Doctoral Training Partnership, Grant/Award NE/L002566/1, CASE award partner the 
National Physical Laboratory (NPL) and by UKRI/Research England SPF funding via the University of Surrey. The APC was funded by the University of Surrey.

Institutional Review Board Statement: Not applicable.

Informed Consent Statement: Not applicable.

Data Availability Statement: Some dataset presented in this study are openly available in [90-93]. Restrictions apply to the availability of the UK CEH LCM2019 and Crops2019 products. Data were obtained from Digimap Edina, available from the https:/ / digimap.edina.ac.uk/ with the permission of University of Surrey.

Acknowledgments: This research was supported by the SCENARIO Doctoral Training Partnership of the UK Natural Environment Research Council (NERC) with PhD funding for the first author. We thank the National Physical Laboratory (NPL) for co-funding as the CASE award partner and, in particular, for co-supervision by Emma Woolliams of NPL for AA's PhD research. We also would like to thank University of Surrey SPF UKRI/Research England support for AA for her secondment "Earth Observation for Advanced Monitoring, Reporting and Verification for Environmental Land Management (ELM) policy in the Surrey Hills Area of Outstanding Natural Beauty (SH-AONB)" to conduct this research with the SH-AONB Defra Test and Trial. We are grateful to the ecological experts for their generous consultations, including Surrey Wildlife Trust, in particular, Mike Waite, and Butterfly Conservation, SH-AONB and its personnel, and the team delivering SH-AONB Nature Recovery Defra Test and Trial. Likewise, Earth-i are acknowledged for provision of the pre-processed VHR satellite imagery and for associated support.

Conflicts of Interest: The authors declare no conflict of interest.

\section{References}

1. Motavalli, P.; Nelson, K.; Udawatta, R.; Jose, S.; Bardhan, S. Global achievements in sustainable land management. Int. Soil Water Conserv. Res. 2013, 1, 1-10. [CrossRef]

2. Schwilch, G.; Bestelmeyer, B.; Bunning, S.; Critchley, W.; Herrick, J.; Kellner, K.; Liniger, H.; Nachtergaele, F.; Ritsema, C.; Schuster, B.; et al. Experiences in monitoring and assessment of sustainable land management. Land Degrad. Dev. 2011, 22, 214-225. [CrossRef]

3. Hans, H. Concepts of sustainable land management. ITC J. 1997, 3/4, 210-215.

4. Zscheischler, J.; Rogga, S. Innovations for Sustainable Land Management-A Comparative Case Study. In Sustainable Land Management in a European Context: A Co-Design Approach; Weith, T., Barkmann, T., Gaasch, N., Rogga, S., Strauß, C., Zscheischler, J., Eds.; Springer International Publishing: New York, NY, USA, 2021; pp. 145-164.

5. World Bank. Sustainable Land Management; The World Bank: Washington, DC, USA, 2006; p. 108.

6. Sustainable Soil and Land Management and Climate Change. Available online: http:/ /www.fao.org/climate-smart-agriculturesourcebook/production-resources/module-b7-soil/chapter-b7-1/en/ (accessed on 29 July 2021).

7. Bryan, B. Incentives, land use, and ecosystem services: Synthesizing complex linkages. Environ. Sci. Policy 2013, 27, 124-134. [CrossRef]

8. Bastidas Fegan, S. The DS-SLM Sustainable Land Management Mainstreaming Tool-Decision Support for Mainstreaming and Scaling up Sustainable Land Management; FAO: Rome, Italy, 2019; p. 44.

9. Environment Bill. Available online: https://services.parliament.uk/bills/2019-21/environment.html (accessed on 29 July 2021$)$.

10. Agriculture Bill. Available online: https://services.parliament.uk/bills/2019-21/agriculture.htm (accessed on 29 July 2021).

11. DEFRA. Available online: https://www.gov.uk/government/publications/environmental-land-management-schemesoverview/environmental-land-management-scheme-overview (accessed on 29 July 2021).

12. Deng, X.; Li, Z.; Gibson, J. A review on trade-off analysis of ecosystem services for sustainable land-use management. J. Geogr. Sci. 2016, 26, 953-968. [CrossRef]

13. Dwyer, J.; Short, C.; Berriet-Solliec, M.; Gael-Lataste, F.; Pham, H.-V.; Affleck, M.; Courtney, P.; Déprès, C. Public Goods and Ecosystem Services from Agriculture and Forestry-Towards a Holistic Approach: Review of Theories and Concepts; European Commission: Brussels, Belgium, 2015; pp. 1-37.

14. Hejnowicz, A.P.; Hartley, S.E. New Directions: A Public Goods Approach to Agricultural Policy Post-Brexit; CECAN: Guildford, UK, 2018; pp. 1-42.

15. Rodgers, C. Delivering a better natural environment? The Agriculture Bill and future agri-environment policy. Environ. Law Rev. 2019, 21, 38-48. [CrossRef]

16. DEFRA. Environmental Land Management: Policy Discussion, ELMS Consulation Document. Available online: https: / / consult.defra.gov.uk/elm/elmpolicyconsultation/supporting_documents/ELM\%20Policy\%20Discussion\%20Document\% 20230620.pdf (accessed on 29 July 2021). 
17. Nelson, E.; Mendoza, G.; Regetz, J.; Polasky, S.; Tallis, H.; Cameron, D.; Chan, K.; Daily, G.C.; Goldstein, J.; Kareiva, P.M.; et al. Modeling multiple ecosystem services, biodiversity conservation, commodity production, and tradeoffs at landscape scales. Front. Ecol. Environ. 2009, 7, 4-11. [CrossRef]

18. Mulligan, M.; van Soesbergen, A.; Hole, D.G.; Brooks, T.M.; Burke, S.; Hutton, J. Mapping nature's contribution to SDG 6 and implications for other SDGs at policy relevant scales. Remote Sens. Environ. 2020, 239, 111671. [CrossRef]

19. Boumans, R.; Roman, J.; Altman, I.; Kaufman, L. The Multiscale Integrated Model of Ecosystem Services (MIMES): Simulating the interactions of coupled human and natural systems. Ecosyst. Serv. 2015, 12, 30-41. [CrossRef]

20. Ivanic, K.-Z.; Stolton, S.; Arango, C.F.; Dudley, N. Protected Areas Benefits Assessment Tool + (PA-BAT+): A Tool to Assess Local Stakeholder Perceptions of the Flow of Benefits from Protected Areas; IUCN, International Union for Conservation of Nature: Gland, Switzerland, 2020; p. 84 .

21. Preston, S.; Raudsepp-Hearne, C. Ecosystem Services Toolkit. Completing and Using Ecosystem Service Assessment for Decision-Making: An Interdisciplinary Toolkit for Managers; European Commission: Brussels, Belgium, 2017.

22. TESSA (Toolkit for Ecosystem Service Site-Based Assessment). Available online: https:/ / ecosystemsknowledge.net/tessa-toolkitecosystem-service-site-based-assessment (accessed on 29 July 2021).

23. MIMES. Available online: https: / /ipbes.net/ar/node/29397?page=15 (accessed on 29 July 2021).

24. ARIES. Available online: https:/ / aries.integratedmodelling.org/ (accessed on 29 July 2021).

25. Neugarten, R.; Langhammer, P.F.; Osipova, E.; Bagstad, K.J.; Bhagabati, N.; Butchart, S.H.; Dudley, N.; Elliott, V.; Gerber, L.R.; Gutiérrez-Arellano, C.; et al. Tools for Measuring, Modelling, and Valuing Ecosystem Services: Guidance for Key Biodiversity Areas, Natural World Heritage Sites, and Protected Areas; IUCN, International Union for Conservation of Nature: Gland, Switzerland, 2018; p. 70.

26. Pan, H.; Zhang, L.; Cong, C.; Deal, B.; Wang, Y. A dynamic and spatially explicit modeling approach to identify the ecosystem service implications of complex urban systems interactions. Ecol. Indic. 2019, 102, 426-436. [CrossRef]

27. Cohen-Shacham, E.; Andrade, A.; Dalton, J.; Dudley, N.; Jones, M.; Kumar, C.; Maginnis, S.; Maynard, S.; Nelson, C.R.; Renaud, F.G.; et al. Core principles for successfully implementing and upscaling Nature-based Solutions. Environ. Sci. Policy 2019, 98, 20-29. [CrossRef]

28. Keesstra, S.; Nunes, J.; Novara, A.; Finger, D.; Avelar, D.; Kalantari, Z.; Cerdà, A. The superior effect of nature based solutions in land management for enhancing ecosystem services. Sci. Total Environ. 2018, 610-611, 997-1009. [CrossRef]

29. Pan, H.; Page, J.; Cong, C.; Barthel, S.; Kalantari, Z. How ecosystems services drive urban growth: Integrating nature-based solutions. Anthropocene 2021, 35, 100297. [CrossRef]

30. Song, Y.; Kirkwood, N.; Maksimović, Č.; Zheng, X.; O'Connor, D.; Jin, Y.; Hou, D. Nature based solutions for contaminated land remediation and brownfield redevelopment in cities: A review. Sci. Total Environ. 2019, 663, 568-579. [CrossRef]

31. Natural Capital Committee. Advice on Using Nature Based Interventions to Reach Net Zero Greenhouse Gas. Emission; UK Department for Environment, Food $\backslash$ Rural Affairs: Westminster, UK, 2020.

32. DEFRA. Environmental Land Management Tests and Trials Quarterly Evidence Report. Available online: https://www.gov.uk/ government/publications/environmental-land-management-tests-and-trials (accessed on 9 June 2021).

33. Surrey Hills AONB. Making Space for Nature. 2020. Available online: https://mk0surreyhillsnfif4k.kinstacdn.com/wp-content/ uploads/2020/02/Item-5-Making-Space-for-Nature.pdf (accessed on 29 July 2021).

34. Sadlier, G.; Flytkjær, R.; Sabri, S.; Robin, N. Value of Satellite-Derived Earth Observation Capabilities to the UK Government Today and by 2020; London Economics: Boston, MA, USA, 2018.

35. Geospatial Commission. Unlocking the Power of Location: The UK's Geospatial Strategy. Available online: https: //www.gov.uk/government/publications/unlocking-the-power-of-locationthe-uks-geospatial-strategy/unlocking-thepower-of-location-the-uks-geospatial-strategy-2020-to-2025 (accessed on 29 July 2021).

36. Kuenzer, C.; Ottinger, M.; Wegmann, M.; Guo, H.; Wang, C.; Zhang, J.; Dech, S.; Wikelski, M. Earth observation satellite sensors for biodiversity monitoring: Potentials and bottlenecks. Int. J. Remote Sens. 2014, 35, 6599-6647. [CrossRef]

37. Lucas, R.; Blonda, P.; Bunting, P.; Jones, G.; Inglada, J.; Arias, M.; Kosmidou, V.; Petrou, Z.I.; Manakos, I.; Adamo, M.; et al. The Earth Observation Data for Habitat Monitoring (EODHaM) system. Int. J. Appl. Earth Obs. Geoinf. 2015, 37, 17-28. [CrossRef]

38. Vihervaara, P.; Auvinen, A.-P.; Mononen, L.; Törmä, M.; Ahlroth, P.; Anttila, S.; Böttcher, K.; Forsius, M.; Heino, J.; Heliölä, J.; et al. How Essential Biodiversity Variables and remote sensing can help national biodiversity monitoring. Glob. Ecol. Conserv. 2017, 10, 43-59. [CrossRef]

39. Rocchini, D.; Marcantonio, M.; Da Re, D.; Chirici, G.; Galluzzi, M.; Lenoir, J.; Ricotta, C.; Torresani, M.; Ziv, G. Time-lapsing biodiversity: An open source method for measuring diversity changes by remote sensing. Remote Sens. Environ. 2019, $231,111192$. [CrossRef]

40. Randin, C.F.; Ashcroft, M.B.; Bolliger, J.; Cavender-Bares, J.; Coops, N.C.; Dullinger, S.; Dirnböck, T.; Eckert, S.; Ellis, E.; Fernández, N.; et al. Monitoring biodiversity in the Anthropocene using remote sensing in species distribution models. Remote Sens. Environ. 2020, 239, 111626. [CrossRef]

41. Townsend, P.A.; Lookingbill, T.R.; Kingdon, C.; Gardner, R.H. Spatial pattern analysis for monitoring protected areas. Remote Sens. Environ. 2009, 113, 1410-1420. [CrossRef] 
42. Sallustio, L.; De Toni, A.; Strollo, A.; Di Febbraro, M.; Gissi, E.; Casella, L.; Geneletti, D.; Munafò, M.; Vizzarri, M.; Marchetti, M. Assessing habitat quality in relation to the spatial distribution of protected areas in Italy. J. Environ. Manag. 2017, 201, 129-137. [CrossRef]

43. Crawford, B.A.; Maerz, J.C.; Moore, C.T. Expert-Informed Habitat Suitability Analysis for At-Risk Species Assessment and Conservation Planning. J. Fish. Wildl. Manag. 2020, 11, 130-150. [CrossRef]

44. Ahmadipari, M.; Yavari, A.; Ghobadi, M. Ecological monitoring and assessment of habitat suitability for brown bear species in the Oshtorankooh protected area, Iran. Ecol. Indic. 2021, 126, 107606. [CrossRef]

45. McMahon, C.R.; Howe, H.; Hoff, J.V.D.; Alderman, R.; Brolsma, H.; Hindell, M. Satellites, the All-Seeing Eyes in the Sky: Counting Elephant Seals from Space. PLoS ONE 2014, 9, e92613. [CrossRef]

46. Fretwell, P.T.; Staniland, I.; Forcada, J. Whales from Space: Counting Southern Right Whales by Satellite. PLoS ONE 2014, 9 , e88655. [CrossRef] [PubMed]

47. Mairota, P.; Cafarelli, B.; Labadessa, R.; Lovergine, F.P.; Tarantino, C.; Lucas, R.; Nagendra, H.; Didham, R.K. Very high resolution Earth observation features for monitoring plant and animal community structure across multiple spatial scales in protected areas. Int. J. Appl. Earth Obs. Geoinf. 2015, 37, 100-105. [CrossRef]

48. Rocchini, D.; Hernandez-Stefanoni, J.L.; He, K.S. Advancing species diversity estimate by remotely sensed proxies: A conceptual review. Ecol. Inform. 2015, 25, 22-28. [CrossRef]

49. Fretwell, P.T.; Trathan, P.N. Discovery of new colonies by Sentinel2 reveals good and bad news for emperor penguins. Remote Sens. Ecol. Conserv. 2021, 7, 139-153. [CrossRef]

50. Räsänen, A.; Aurela, M.; Juutinen, S.; Kumpula, T.; Lohila, A.; Penttilä, T.; Virtanen, T. Detecting northern peatland vegetation patterns at ultra-high spatial resolution. Remote Sens. Ecol. Conserv. 2020, 6, 457-471. [CrossRef]

51. Klimetzek, D.; Stăncioiu, P.T.; Paraschiv, M.; Niță, M.D. Ecological Monitoring with Spy Satellite Images-The case of Red Wood Ants in Romania. Remote Sens. 2021, 13, 520. [CrossRef]

52. Rotenberry, J.T.; Preston, K.L.; Knick, S.T. Gis-Based Niche Modeling for Mapping Species' Habitat. Ecology 2006, 87, 1458-1464. [CrossRef]

53. Turner, W.; Spector, S.; Gardiner, N.; Fladeland, M.; Sterling, E.; Steininger, M. Remote sensing for biodiversity science and conservation. Trends Ecol. Evol. 2003, 18, 306-314. [CrossRef]

54. Haines-Young, R.H.; Potschin, M.B.; Deane, R.; Porter, K. Policy Impact and Future Options for Countryside Survey. Final Report. Available online: https://www.nottingham.ac.uk/cem/pdf/FOFCS_FinalReport_Revised_August2014.pdf (accessed on 29 July 2021).

55. Morton, R.D.; Rowland, C.S. Developing and Evaluating an Earth Observation-enabled ecological land cover time series system. JNCC Rep. 2015, 563, 2-7.

56. Morton, R.D.; Marston, C.G.; O’Neil, A.W.; Rowland, C.S. Land Cover Map 2019 (land parcels, GB). NERC Environ. Inf. Data Cent. 2020. [CrossRef]

57. Feranec, J.M.G.; Hazeu, G. European Landscape Dynamics (Chapter 5. Interpretation of Satellite Images); Taylor \& Francis: Oxfordshire, UK, 2016; pp. 33-41.

58. UN. Earth Observations for Official Statistics Satellite Imagery and Geospatial Data Task Team Report; United Nations Satellite Imagery and Geo-spatial Data Task Team: Rio de Janeiro, Brazil, 2017; p. 170.

59. Svatonova, H. Analysis of Visual Interpretation of Satellite Data. ISPRS-Int. Arch. Photogramm. Remote Sens. Spat. Inf. Sci. 2016, $X L I-B 2,675-681$. [CrossRef]

60. Campbell, J.B.; Wynne, R.H. Introduction to Remote Sensing, 5th ed.; The Guilford Press: New York, NY, USA, 2011 ; pp. $130-158$.

61. Thomas, N.P.; Benning, I.L.; Ching, V.M. Classification of Remotely Sensed Images; Taylor \Francis: Oxfordshire, UK, 1987 ; p. 267.

62. Ibarrola-Ulzurrun, E.; Marcello, J.; Gonzalo-Martin, C. Assessment of Component Selection Strategies in Hyperspectral Imagery. Entropy 2017, 19, 666. [CrossRef]

63. Kumar, P.S.J.; Huan, T.L. Earth Science and Remote Sensing Applications; Springer: Berlin/Heidelberg, Germany, 2018.

64. Anderson, C.B. Biodiversity monitoring, earth observations and the ecology of scale. Ecol. Lett. 2018, 21, 1572-1585. [CrossRef]

65. Ernst, C.; Mayaux, P.; Verhegghen, A.; Bodart, C.; Christophe, M.; Defourny, P. National forest cover change in Congo Basin: Deforestation, reforestation, degradation and regeneration for the years 1990, 2000 and 2005. Glob. Chang. Biol. 2013, 19, 1173-1187. [CrossRef] [PubMed]

66. Nagendra, H.; Mairota, P.; Marangi, C.; Lucas, R.; Dimopoulos, P.; Honrado, J.; Niphadkar, M.; Mucher, S.; Tomaselli, V.; Panitsa, M.; et al. Satellite Earth observation data to identify anthropogenic pressures in selected protected areas. Int. J. Appl. Earth Obs. Geoinf. 2015, 37, 124-132. [CrossRef]

67. Adamo, M.; Tomaselli, V.; Tarantino, C.; Vicario, S.; Veronico, G.; Lucas, R.; Blonda, P. Knowledge-Based Classification of Grassland Ecosystem Based on Multi-Temporal WorldView-2 Data and FAO-LCCS Taxonomy. Remote Sens. 2020, $12,1447$. [CrossRef]

68. DEFRA. Roadmap for the Use of Earth Observation across Defra 2015-2020 Report. Available online: https://assets.publishing. service.gov.uk/government/uploads/system/uploads/attachment_data/file/488133/defra-earth-obs-roadmap-2015.pdf (accessed on 29 July 2021).

69. Secades, C.; O'Connor, B.; Brown, C.; Walpole, M. Review of the Use of Remotely-Sensed Data for Monitoring Biodiversity Change and Tracking Progress towards the Aichi Biodiversity Targets; UNEP-WCMC: Cambridge, UK, 2014; p. 183. 
70. Barbosa, C.D.A.; Atkinson, P.; Dearing, J. Remote sensing of ecosystem services: A systematic review. Ecol. Indic. 2015, 52, 430-443. [CrossRef]

71. SIRS. Feasibility Study about the Mapping and Monitoring of Green Linear Features Based on VHR Satellites Imagery. Available online: https:/ / land.copernicus.eu/user-corner/technical-library/study-lead-by-sirs (accessed on 29 July 2021).

72. Making Earth Observation Work (MEOW) for UK Biodiversity Monitoring and Surveillance, Phase 4: Testing Applications in Habitat Condition Assessment A Report to the Department for Environment, Food and Rural Affairs, Prepared by Environment Systems. Available online: http:/ / randd.defra.gov.uk/Document.aspx?Document=13900_BE0119_MEOW4_Report_Final.pdf (accessed on 29 July 2021).

73. Anderson, J.R.; Hardy, E.E.; Roach, J.T.; Witmer, R.E. A Land Use and Land Cover Classification System for Use with Remote Sensor Data; US Government Printing Office: Washington, DC, USA, 1976.

74. Yang, H.; Li, S.; Chen, J.; Zhang, X.; Xu, S. The Standardization and Harmonization of Land Cover Classification Systems towards Harmonized Datasets: A Review. ISPRS Int. J. Geo-Inf. 2017, 6, 154. [CrossRef]

75. Jansen, L.J.; Di Gregorio, A. Land-use data collection using the "land cover classification system": Results from a case study in Kenya. Land Use Policy 2003, 20, 131-148. [CrossRef]

76. Headquarters, C.; Skole, D.; Salas, W.; Taylor, V. Global Observation of Forest Cover: Fine Resolution Data and Product Design Strategy, Report of a Workshop; GOFC-GOLD: Washington, DC, USA, 1998.

77. Global Observation for Forest Cover and Land Dynamics (GOFC/GOLD). Available online: http://www.gofcgold.wur.nl (accessed on 19 July 2021).

78. Venter, Z.; Sydenham, M. Continental-Scale Land Cover Mapping at $10 \mathrm{~m}$ Resolution over Europe (ELC10). Remote Sens. 2021, 13, 2301. [CrossRef]

79. Africover. Available online: http:/ /www.fao.org/3/bd854e/bd854e.pdf (accessed on 29 July 2021).

80. National Land Cover Database 2019 (NLCD2019) Legend. Available online: https://www.mrlc.gov/data/legends/nationalland-cover-database-2019-nlcd2019-legend (accessed on 29 July 2021).

81. National Land Use Database: Land Use and Land Cover Classification. Available online: https:/ /assets.publishing.service.gov. uk/government/uploads/system/uploads/attachment_data/file/11493/144275.pdf (accessed on 29 July 2021).

82. Jackson, D.L. Guidance on the Interpretation of the Biodiversity Broad Habitat Classification (Terrestrial and Freshwater Types): Definitions and the Relationship with Other Classifications. JNCC Report No. 307, JNCC, Peterborough. Available online: https:/ / data.jncc.gov.uk/data/0b7943ea-2eee-47a9-bd13-76d1d66d471f/JNCC-Report-307-SCAN-WEB.pdf (accessed on 29 July 2021).

83. Society, T.R. Observing the Earth: Expert Views on Environmental Observation for the UK. Available online: https://royalsociety. org/-/media/policy/projects/environmental-observation/environmental-observations-report.pdf (accessed on 29 July 2021).

84. Tansey, K.; Chambers, I.; Anstee, A.; Denniss, A.; Lamb, A. Object-oriented classification of very high resolution airborne imagery for the extraction of hedgerows and field margin cover in agricultural areas. Appl. Geogr. 2009, 29, 145-157. [CrossRef]

85. Pettorelli, N.; Safi, K.; Turner, W. Satellite remote sensing, biodiversity research and conservation of the future. Philos. Trans. R. Soc. B Biol. Sci. 2014, 369, 20130190. [CrossRef]

86. SH AONB Surrey Hills Management Plan 2020-2025. Available online: https://mk0surreyhillsnfif4k.kinstacdn.com/wp-content/ uploads/2019/12/Surrey-Hills-Management-Plan-Web-72-SP-1.pdf (accessed on 29 July 2021).

87. Trust, S.W. Biodiversity and Planning in Surrey. Available online: https://surreynaturepartnership.files.wordpress.com/2019/1 0/biodiversity-planning-in-surrey-revised_post-revision-nppf_mar-2019.pdf (accessed on 29 July 2021).

88. Morton, R.D.; Marston, C.G.; O’Neil, A.W.; Rowland, C.S. Land Cover Map 2017, 2018, 2019 (25 m Rasterised Land Parcels, GB); NERC Environmental Information Data Centre: Lancaster, UK, 2020. [CrossRef]

89. DigiMap EDINA. Available online: https:/ /digimap.edina.ac.uk (accessed on 29 July 2021).

90. Open Government Licence, Priority Habitat Inventory (England). Available online: https://data.gov.uk/dataset/4b6ddab7-6c0f4407-946e-d6499f19fcde/ priority-habitat-inventory-england (accessed on 29 July 2021).

91. Export Open Street Map. Available online: https://www.openstreetmap.org/export\#map=6/42.088/12.564 (accessed on 4 September 2020).

92. Google Earth Engine. Available online: https:/ / explorer.earthengine.google.com/\#workspace (accessed on 29 July 2021$).$

93. Farr, T.G.; Rosen, P.A.; Caro, E.; Crippen, R.; Duren, R.; Hensley, S.; Kobrick, M.; Paller, M.; Rodriguez, E.; Roth, L.; et al. The Shuttle Radar Topography Mission. Rev. Geophys. 2007, 45, 2. [CrossRef]

94. Garibaldi, A.; Turner, N. Cultural Keystone Species: Implications for Ecological Conservation and Restoration. Ecol. Soc. 2004, 9 , 3. [CrossRef]

95. Hötker, H.; Oppermann, R.; Jahn, T.; Bleil, R. Protection of biodiversity of free living birds and mammals in respect of the effects of pesticides. Jul.-Kühn-Arch. 2013, 442, 91-92.

96. Donald, P.; Buckingham, D.; Moorcroft, D.; Muirhead, L.; Evans, A.; Kirby, W. Habitat use and diet of skylarks Alauda arvensis wintering on lowland farmland in southern Britain. J. Appl. Ecol. 2001, 38, 536-547. [CrossRef]

97. Chamberlain, D.E.; Crick, H.Q. Population declines and reproductive performance of Skylarks Alauda arvensis in different regions and habitats of the United Kingdom. IBIS 2008, 141, 38-51. [CrossRef]

98. Wilson, J.D.; Evans, J.; Browne, S.J.; King, J.R. Territory Distribution and Breeding Success of Skylarks Alauda arvensis on Organic and Intensive Farmland in Southern England. J. Appl. Ecol. 1997, 34, 1462. [CrossRef] 
99. Murray, K.A. Factors Affecting Foraging by Breeding Farmland Birds; Open University: Buckinghamshire, UK, 2004.

100. Sozio, G.; Iannarilli, F.; Melcore, I.; Boschetti, M.; Fipaldini, D.; Luciani, M.; Roviani, D.; Schiavano, A.; Mortelliti, A. Forest management affects individual and population parameters of the hazel dormouse Muscardinus avellanarius. Mamm. Biol. 2016, 81, 96-103. [CrossRef]

101. Trout, R.C.; Brooks, S.E.; Rudlin, P.; Neil, J. The effects of restoring a conifer Plantation on an Ancient Woodland Site (PAWS) in the UK on the habitat and local population of the Hazel Dormouse (Muscardinus avellanarius). Eur. J. Wildl. Res. 2012, 58, 635-643. [CrossRef]

102. Goodwin, C.E.D.; Hodgson, D.J.; Al-Fulaij, N.; Bailey, S.; Langton, S.; McDonald, R.A. Voluntary recording scheme reveals ongoing decline in the United Kingdom hazel dormouse Muscardinus avellanarius population. Mammal. Rev. 2017, 47, 183-197. [CrossRef]

103. Goodwin, C.E.D.; Suggitt, A.J.; Bennie, J.; Silk, M.J.; Duffy, J.P.; Al-Fulaij, N.; Bailey, S.; Hodgson, D.J.; McDonald, R.A. Climate, landscape, habitat, and woodland management associations with hazel dormouse Muscardinus avellanarius population status. Mammal. Rev. 2018, 48, 209-223. [CrossRef]

104. Otto, C.R.V.; Roth, C.; Carlson, B.L.; Smart, M.D. Land-use change reduces habitat suitability for supporting managed honey bee colonies in the Northern Great Plains. Proc. Natl. Acad. Sci. USA 2016, 113, 10430-10435. [CrossRef]

105. Andrew, M.E.; Ustin, S. Habitat suitability modelling of an invasive plant with advanced remote sensing data. Divers. Distrib. 2009, 15, 627-640. [CrossRef]

106. Gomez, J.J.; Túnez, J.I.; Fracassi, N.; Cassini, M.H. Habitat suitability and anthropogenic correlates of Neotropical river otter (Lontra longicaudis) distribution. J. Mammal. 2014, 95, 824-833. [CrossRef]

107. Duro, D.; Franklin, S.; Dubé, M.G. A comparison of pixel-based and object-based image analysis with selected machine learning algorithms for the classification of agricultural landscapes using SPOT-5 HRG imagery. Remote Sens. Environ. 2012, 118, 259-272. [CrossRef]

108. Cord, A.F.; Brauman, K.; Chaplin-Kramer, R.; Huth, A.; Ziv, G.; Seppelt, R. Priorities to Advance Monitoring of Ecosystem Services Using Earth Observation. Trends Ecol. Evol. 2017, 32, 416-428. [CrossRef] [PubMed]

109. Cochran, F.; Daniel, J.; Jackson, L.; Neale, A. Earth observation-based ecosystem services indicators for national and subnational reporting of the sustainable development goals. Remote Sens. Environ. 2020, 244, 111796. [CrossRef] [PubMed]

110. Watmough, G.R.; Marcinko, C.L.J.; Sullivan, C.; Tschirhart, K.; Mutuo, P.K.; Palm, C.A.; Svenning, J.-C. Socioecologically informed use of remote sensing data to predict rural household poverty. Proc. Natl. Acad. Sci. USA 2019, 116, 1213-1218. [CrossRef] [PubMed] 